\title{
miR126-5p Downregulation Facilitates Axon Degeneration and NMJ Disruption via a Non-Cell-Autonomous Mechanism in ALS
}

\author{
ㅈoy Maimon, ${ }^{1 \star}$ Ariel Ionescu, ${ }^{1 \star}$ Avichai Bonnie, ${ }^{1}$ Sahar Sweetat, ${ }^{2}$ Shane Wald-Altman, ${ }^{3}$ Shani Inbar, ${ }^{3}$ Tal Gradus, ${ }^{1}$ \\ (DDavide Trotti, ${ }^{4}$ Miguel Weil, ${ }^{3}$ Doded Behar, ${ }^{2}$ and Eran Perlson ${ }^{1}$ \\ ${ }^{1}$ Department of Physiology and Pharmacology, Sackler Faculty of Medicine, Tel Aviv University, Tel Aviv 69978, Israel, ${ }^{2}$ Department of Developmental \\ Biology and Cancer Research, Hebrew University of Jerusalem, Jerusalem 9190401 Israel, ${ }^{3}$ Department of Cell Research and Immunology, Tel Aviv \\ University, Tel Aviv 69978, Israel, and ${ }^{4}$ Jefferson Weinberg ALS Center, Vickie and Jack Farber Institute for Neuroscience, Department of Neuroscience, \\ Thomas Jefferson University, Philadelphia, Pennsylvania 19107
}

Axon degeneration and disruption of neuromuscular junctions (NMJs) are key events in amyotrophic lateral sclerosis (ALS) pathology. Although the disease's etiology is not fully understood, it is thought to involve a non-cell-autonomous mechanism and alterations in RNA metabolism. Here, we identified reduced levels of miR126-5p in presymptomatic ALS male mice models, and an increase in its targets: axon destabilizing Type 3 Semaphorins and their coreceptor Neuropilins. Using compartmentalized in vitro cocultures, we demonstrated that myocytes expressing diverse ALS-causing mutations promote axon degeneration and NMJ dysfunction, which were inhibited by applying Neuropilin1 blocking antibody. Finally, overexpressing miR126-5p is sufficient to transiently rescue axon degeneration and NMJ disruption both in vitro and in vivo. Thus, we demonstrate a novel mechanism underlying ALS pathology, in which alterations in miR126-5p facilitate a non-cell-autonomous mechanism of motor neuron degeneration in ALS.

Key words: ALS; axon degeneration; microfluidic chambers; miRNA; NMJ; Sema3A

Significance Statement

Despite some progress, currently no effective treatment is available for amyotrophic lateral sclerosis (ALS). We suggest a novel regulatory role for miR126-5p in ALS and demonstrate, for the first time, a mechanism by which alterations in miR126-5p contribute to axon degeneration and NMJ disruption observed in ALS. We show that miR126-5p is altered in ALS models and that it can modulate Sema3 and NRP protein expression. Furthermore, NRP1 elevations in motor neurons and muscle secretion of Sema3A contribute to axon degeneration and NMJ disruption in ALS. Finally, overexpressing miR126-5p is sufficient to transiently rescue NMJ disruption and axon degeneration both in vitro and in vivo.

\section{Introduction}

Amyotrophic lateral sclerosis (ALS) is a lethal neurodegenerative disease that affects motor neurons (MNs) in the cortex, brains-

Received Oct. 22, 2017; revised April 15, 2018; accepted April 23, 2018.

Author contributions: R.M., A.I.,M.W., O.B., and E.P. designed research; R.M., A.I., A.B., S.S., S.I., S.W.-A., and T.G. performed research; S.W.-A., D.T., and M.W. contributed unpublished reagents/analytic tools; R.M., A.I., A.B., S.S., S.I., T.G., O.B., and E.P. analyzed data; R.M., A.I., M.W., O.B., and E.P. wrote the paper.

This work was supported by the Rosetrees Trust, Alfred Taubman, the IsrALS Foundation, Israel Science Foundation Grant 561-11, and European Research Council Grant 309377 to E.P., Israel Science Foundation Grant 947/14 to 0.B., and National Institutes of Health Grant R01-NS44292 to D.T. We thank Dr. Eran Horenstein for miR126 and miR 142 , as well as for extra SOD ${ }^{693 A}$ mice; Dr. Mickey Harlev and Lior Bikovski for assisting with mouse injection and the behavioral tests; and Konstantin Voloshin for help in NMJ analysis.

The authors declare no competing financial interests.

*R.M. and A.I. contributed equally to this work.

Correspondence should be addressed to either of the following: Dr. Eran Perlson, Department of Physiology and Pharmacology, Sackler Faculty of Medicine, Tel Aviv University, Room 605, Sagol School of Neuroscience, Ramat tem, and spinal cord (SC) (Mulder et al., 1986; Peters et al., 2015). It is characterized by neuromuscular junction (NMJ) disruption, MN axon degeneration, and neuronal death (Frey et al., 2000; Fischer et al., 2004; Moloney et al., 2014). Despite some progress, currently no effective treatment is available for ALS. The diversity of ALS-related mutations has given rise to the use of numerous animal models with diverse phenotypes, ranging from no effect on $\mathrm{MN}$ function to severe progressive paralysis (Philips and

Aviv, Tel Aviv 69978, Israel, E-mail: eranpe@post.tau.ac.il; or Dr. Oded Behar, Department of Developmental Biology and Cancer Research, Hebrew University of Jerusalem, Ein Kerem, P.0. Box 12271, Jerusalem, 91120 Israel, E-mail: odedb@ekmd.huji.ac.il.

D0I:10.1523/JNEUROSCI.3037-17.2018

Copyright $\odot 2018$ Maimon et al.

This is an open-access article distributed under the terms of the Creative Commons Attribution License Creative Commons Attribution 4.0 International, which permits unrestricted use, distribution and reproduction in any medium provided that the original work is properly attributed. 
Rothstein, 2015). Approximately $20 \%$ of familial ALS is accounted for by mutations in the superoxide dismutase 1 (SOD1) gene (Scrutton et al., 1992; Rosen et al., 1993; Gurney et al., 1994). Mutations in the SOD1 gene (mSOD1) have also been described in sporadic cases (sALS) (Rakhit et al., 2004). Other mutations found in ALS patients include hexanucleotide expansion repeats in the C9orf72 locus, which lead to various dipeptide repeats (e.g., proline-arginine or glycine-arginine repeats: $\mathrm{PR}_{50}$ and $\mathrm{GR}_{50}$, respectively), and in the gene encoding the TDP43 RNA binding protein (Buratti, 2015; Wen et al., 2017). An efficient method for studying NMJ stability and health in vitro is by using the microfluidic chamber (MFC) system, which allows the culture of primary myocytes in one compartment, and MNs in the other, thus setting up conditions conducive to generating active NMJs ( $\mathrm{Za}-$ havi et al., 2015).

The neurodegeneration that occurs in ALS is considered to be a non-cell-autonomous process involving interactions between the neuron and its diverse extracellular microenvironments via an unknown mechanism (Ilieva et al., 2009; Tsitkanou et al., 2016). Although the molecular basis for neuronal dysfunction and death in ALS is still poorly understood, it may be due to alterations in the nature of the extracellular signaling pathways that switch from prosurvival to toxic (Ilieva et al., 2009; Perlson et al., 2009). Numerous studies support the notion that multiple tissues outside the CNS, including skeletal muscle (Dupuis et al., 2006; Tsitkanou et al., 2016), astrocytes (Nagai et al., 2007), and microglia (Lee et al., 2016), contribute to ALS pathologies. Alterations in RNA metabolism and microRNAs (miRs) can contribute to, and also be part of, mechanisms that initiate the disease (Lemmens et al., 2010; Emde and Hornstein, 2014). miRs are post-transcriptional regulators that play an important role in many cellular processes, such as axon growth and retraction, and were demonstrated to be involved in many diseases, including neurodegenerative diseases, such as ALS (Hawley et al., 2017; Molasy et al., 2017). Alterations in miR expression profile were identified specifically in axons of ALS models (Rotem et al., 2017), as well in muscles leading to increasing attempts to either use or target miRs as therapeutic strategies (Di Pietro et al., 2017). Therefore, it is reasonable to assume that alterations in RNA and miRNA metabolism, of both MNs and neighboring cells, can regulate a secreted destabilizing signal, which in turn, facilitates axon degeneration and NMJ disruption.

Semaphorin3A (Sema3A) was initially identified as a repellent guidance molecule (Luo et al., 1993; Worzfeld and Offermanns, 2014). However, later works showed that it can also induce neuronal cell death of sympathetic, sensory, retinal, and cortical neurons (Nakamura et al., 2000; Shirvan et al., 2002; Ben-Zvi et al., 2008; Jiang et al., 2010). Neuropilin1 (NRP1) has been shown to be the receptor binding component for Sema3A as well as some other Type 3 Semaphorins (Kolodkin et al., 1997). Sema3A was found to be upregulated following CNS injury as well as in several neurodegenerative diseases (Kaneko et al., 2006; Van Battum et al., 2015). Importantly, Sema3A was found to be upregulated in terminal Schwann cells of the SOD $1^{G 93 A}$ transgenic mouse model for ALS and in the motor cortex of ALS patients (De Winter et al., 2006; Körner et al., 2016), suggesting that it plays a toxic role in disease pathology and progression.

Here we demonstrated that alterations in miR126-5p result in upregulation of Type 3 Semaphorins and its cobinding receptor NRP1 in muscles and MN axons of ALS models, respectively. We further demonstrate in vitro and in vivo the contribution of this pathway to axon degeneration and NMJ disruption in ALS models.

\section{Materials and Methods}

Animals and vector injections. HB9::GFP (stock \#005029) mice were originally obtained from The Jackson Laboratory. The colony was maintained by breeding with ICR mice. SOD $1^{\text {G93A }}$ (stock \#002726) mice were originally obtained from The Jackson Laboratory and maintained by breeding with C57BL/6J mice. Genotyping was performed using the PCR (KAPA Biosystems); DNA samples were generated from ear or tail tissue biopsies. All injection procedures were performed on presymptomatic $\sim$ P60 mice. Mice were first anesthetized using a mixture of xylazine and ketamine. Next, $100 \mu \mathrm{l}$ of Neurobasal-containing X10 concentrated lentiviruses $\left(6 \times 10^{9}\right.$ titer units) was injected into the gastrocnemius (GC) muscles using a $1 \mathrm{ml}$ syringe and a $25 \mathrm{G}$ needle. A pLL-miR126-5p-GFP construct was injected into the right hind foot, whereas a pLL-miR142GFP construct was injected into the left hind foot. All animal experimentations were approved by the Tel Aviv University Animal Ethics Committee.

MFC preparation. Polydimethylsilxane MFCs were designed and cast as described previously (Ionescu et al., 2016). After the wells were punched, a small "cave" was created in the explant well near the grooves using a $25 \mathrm{G}$ needle, keeping the explant in place. Microfluidic devices were cleaned of surface particles using adhesive tape and were sterilized in 70\% ethanol for $15 \mathrm{~min}$. Devices were completely dried under sterile conditions using UV radiation and then attached to a sterile $60 \mathrm{~mm}$ plastic dish (Nunc) with gentle pressure, and the margins were sealed with polydimethylsilxane before incubation at $70^{\circ} \mathrm{C}$ for $30 \mathrm{~min}$ to prevent the detachment of the chamber. Muscle channels were coated with Matrigel diluted 1:10 with DMEM containing 2.5\% penicillinstreptomycin-nystatin (PSN) for $30 \mathrm{~min}$ at $37^{\circ} \mathrm{C}$, before filling the muscle wells with $150 \mu \mathrm{l}$ of Bioamf-2 medium. The explant well and channel were filled with $150 \mu \mathrm{l}$ of $1.5 \mathrm{ng} / \mathrm{ml}$ poly-DL-ornithine (P-8638, SigmaAldrich) in PBS overnight and then replaced with $150 \mu$ l laminin (L2020, Sigma-Aldrich), 1:333 in deionized distilled water overnight. One day before plating the SC explant, laminin was replaced with explant medium containing Neurobasal (Invitrogen) supplemented with 2\% B27 (Invitrogen), 1\% penicillin-streptomycin (Biological Industries), $1 \%$ Glutamax (Invitrogen), and $25 \mathrm{ng} / \mathrm{ml}$ BDNF (Alomone Labs), until the day on which coculturing began.

Fluorescence microscopy and image analysis. All confocal images were captured using a Nikon Ti microscope equipped with a Yokogawa CSU X-1 spinning disc and an Andor iXon897 EMCCD camera controlled by Andor IQ2 software. Epifluorescence was imaged using the same microscope in bright-field mode, and images were captured with an Andor Neo sCMOS camera, or at a FLoid benchtop imaging station (Invitrogen). TIRF images were captured using a TILL photonics iMIC microscope (FEI Munich) with an Andor iXon897 EMCCD camera. All live-imaging assays were performed in a humidified $5 \% \mathrm{CO}_{2}$ incubation chamber.

Western blotting. Muscle and sciatic nerve ( $\mathrm{SN})$ tissues of both sexes were excised and homogenized in lysis buffer containing PBS, $1 \%$ Triton X-100 (Sigma-Aldrich), and $1 \times$ protease inhibitors (Roche Diagnostics), followed by centrifugation and collection of the supernatant. Protein concentration was determined using the Bio-Rad Protein Assay. Protein samples were denatured by boiling in SDS sample buffer, which were then electrophoresed in $10 \%$ polyacrylamide gels (SDS-PAGE). Proteins were transferred to a nitrocellulose membrane and then immunoblotted with appropriate primary antibodies: Sema3A (Abcam, ab23393; 1:1000); NRP1 (Abcam, ab81321; 1:1000); Sema3B (Abcam, ab48197; 1:2000); NRP2 (Cell Signaling D39A5, 1: 1000); GFP (Abcam ab13970; $1: 5000)$; tubulin $(1: 10,000)$ and ERK $(1: 10,000)$, diluted in $5 \%(\mathrm{w} / \mathrm{v})$ skim milk (BD Difco) in TBS-T, followed by species-specific HRPconjugated secondary antibodies (Jackson ImmunoResearch Laboratories; $1: 10,000$ ) and visualized using a myECL imager (Thermo Fisher Scientific), according to the manufacturer's instructions. Quantification was performed using ImageJ software.

Isolation and culture of human mesenchymal stem cells (hMSCs). hMSCs from healthy donors and ALS patients used in this study were obtained from bone marrow samples and were isolated, and then phenotypically characterized and cultured as described previously (Nachmany et al., 2012). All volunteers in this work signed a consent form 
before sample donation, according to the guidelines of the Hospital's Ethics Committee supervised by the Israeli Health Ministry Ethics Committee conforming with the Code of Ethics of the World Medical Association (Declaration of Helsinki), printed in the British Medical Journal (Rickham, 1964).

MN cell culture. Primary SC neurons were cultured using E12.5 mouse embryos of either sex as previously described (Zahavi et al., 2015). Briefly, SCs were excised, trypsinized, and triturated. Supernatant was collected and centrifuged through a $4 \%$ BSA cushion. The pellet was resuspended and centrifuged through an OptiPrep gradient $(10.4 \%$ OptiPrep, Sigma-Aldrich; $10 \mathrm{~mm}$ Tricine, $4 \%$ glucose) for $20 \mathrm{~min}$ at $760 \times g$ with the brake turned off. Cells were collected from the interface, washed once in complete medium, and then plated in coated growth chambers. Cells were maintained in Complete Neurobasal Medium (Invitrogen) containing B27 (Invitrogen), 10\% (v/v) horse serum (Biological Industries), $25 \mathrm{~nm} \beta$-mercaptoethanol, $1 \%$ penicillin-streptomycin (PS; Biological Industries), and 1\% GlutaMAX (Invitrogen) supplemented with $1 \mathrm{ng} / \mathrm{ml}$ GDNF, $0.5 \mathrm{ng} / \mathrm{ml} \mathrm{CNTF}$, and $1 \mathrm{ng} / \mathrm{ml}$ BDNF (Alomone Labs). Before plating, the growth plates were coated with $1.5 \mathrm{~g} / \mathrm{ml}$ poly-DL-ornithine (Sigma-Aldrich) overnight at $37^{\circ} \mathrm{C}$ and $3 \mathrm{~g} / \mathrm{ml} \mathrm{laminin}$ (Sigma-Aldrich) for $2 \mathrm{~h}$ at $37^{\circ} \mathrm{C}$. For immunofluorescence staining, 30,000 cells were plated on cover slides in 24 -well plates. Cells were grown at $37^{\circ} \mathrm{C}$ in $5 \% \mathrm{CO}_{2}$.

SC explants. SCs were dissected from E11.5 mouse embryos of both sexes, either using HB9::GFP or SOD1 ${ }^{\text {G93A }}$ stripped of meninges and DRGs. The ventral horn was separated from the dorsal horn by longitudinal cuts along the SC, and transverse sections up to $1 \mathrm{~mm}$ were placed in the explant well. Before plating, the growth chambers were coated with $1.5 \mathrm{~g} / \mathrm{ml}$ poly-DL-ornithine overnight at $37^{\circ} \mathrm{C}$ and $3 \mathrm{~g} / \mathrm{ml}$ laminin overnight at $37^{\circ} \mathrm{C}$. Explants were maintained in Spinal Cord Explant Medium containing Neurobasal, 2\% B27, 1\% PS, and 1\% GlutaMAX, supplemented with $25 \mathrm{ng} / \mathrm{ml}$ BDNF. Explants were grown at $37^{\circ} \mathrm{C}$ in $5 \% \mathrm{CO}_{2}$.

Primary myocyte culture. Skeletal muscle cultures were derived from the GC muscle of adult P60 female mice of either SOD $1^{\text {G93A }}$ background or their littermates (LMs) using techniques previously described (Ionescu et al., 2016). Briefly, GC muscles were excised and incubated in 2 $\mathrm{mg} / \mathrm{ml}$ collagenase I (Sigma-Aldrich) in DMEM containing 2.5\% PSN (Biological Industries) for $3 \mathrm{~h}$. Muscles were then dissociated and incubated for $3 \mathrm{~d}$ in Matrigel-coated (BD Biosciences) 6-well plates with Bioamf-2 medium (Biological Industries) with $1 \%$ PSN at a density of $\sim 120$ myofibers per well. For purification of the myoblasts, adherent cells were trypsinized and preplated in an uncoated dish for $1 \mathrm{~h}$ at $37^{\circ} \mathrm{C}$. Nonadherent cells were then transferred into a Matrigel-coated dish with Bioamf- 2 medium. Preplating was repeated for $2 \mathrm{~d}$, keeping the culture at $<50 \%$ confluence, before plating cells in MFC. Cultures were maintained at $37^{\circ} \mathrm{C}$ and in $5 \% \mathrm{CO}_{2}$. After the final preplating, 100,000 myocytes were cultured in the precoated distal compartment of the MFC. Myocyte conditioned media (CM) were produced as follows: At the final preplating stage, myoblasts were cultured in a Matrigel-coated $100 \mathrm{~mm}$ dish at $80 \%$ confluence and were incubated for $2 \mathrm{~d}$ with Bioamf- 2 medium, followed by $2 \mathrm{~d}$ with rich DMEM (Biological Industries) medium containing 10\% FCS (Biological Industries), 10\% horse serum (Biological Industries), $1 \%$ GlutaMAX, and 1\% PSN. Then, once muscles reached a fully differentiated state, the culture dish was rinsed 3 times with preheated PBS and poor DMEM containing 1\% GlutaMAX, and $1 \%$ PSN was applied on the cultures. CM was collected after $2 \mathrm{~d}$, centrifuged for $5 \mathrm{~min}$ at $400 \times g$ at $25^{\circ} \mathrm{C}$, and streamed through a $0.22 \mu \mathrm{m}$ PES filter.

$C M$ preparation and application. Muscle myocytes of WT or SOD ${ }^{G 93 A}$ mice were cultured as described previously (Ionescu et al., 2016). Seven days after myocytes were fully differentiated, the muscles kept growing for $3 \mathrm{~d}$ in complete Neurobasal containing BDNF and GDNF. The CM was refreshed with BDNF, GDNF, and glucose after its collection, as described previously (Nagai et al., 2007). CM under both conditions was applied on the axon compartment of the MFC for $48 \mathrm{~h}$.

Lentiviral vectors. Genes of interest were cloned into a third-generation lentiviral pLL3.7 backbone. HEK293T cells were transfected by using calcium phosphate method and a mixture consisting of the vector of interest, vesicular stomatitis virus glycoprotein, and group antigenspolymerase (reverse transcriptase) was used. The medium was replaced after 5-8 h, and the supernatant was collected $48 \mathrm{~h}$ later. Next, $50 \mathrm{~mm}$ HEPES was added before freezing to maintain a neutral $\mathrm{pH}$ for long-term storage. When necessary, lentiviruses were concentrated using a PEG Virus Precipitation Kit (Abcam).

NMJ staining. GC was excised from P60 mice and cleared of connective tissue, washed in PBS, fixed in 4\% PFA, washed once more, and then incubated with $1 \mathrm{~g} / \mathrm{ml}$ Rhodamine Red-Conjugated Bungarotoxin (Sigma-Aldrich). Tissues were washed and then treated with methanol at $-20^{\circ} \mathrm{C}$ for $5 \mathrm{~min}$, washed, and then blocked in blocking solution for $1 \mathrm{~h}$. Tissues were then rocked with appropriate primary antibodies diluted in blocking solution at room temperature overnight. Antibodies were used at the following concentrations: anti-Neurofilament Heavy Chain 1:500 (NFH, Abcam, ab72996; 1:1000), synaptophysin (Millipore, MAB5258; 1:300), synaptotagmin (Alomone Labs, ant-003; 1:300), anti-NRP1 (1: 100), anti-Sema3A (1:100), anti-NRP2 (1:100), and anti-Sema3B (1: 100). After having been washed, secondary antibodies (DyLight 405 antichicken 1:500; AlexaFluor-488 anti-chicken 1:500; AlexaFluor-647 antirabbit 1:500) were added for $4 \mathrm{~h}$ at room temperature. Muscle fibers were spread into monolayers under a stereomicroscope and affixed to slides using VectaShield (Vector Laboratories). Cover slides were sealed with clear nail polish.

Quantification of myocyte contraction. The 1000-frame-long movies of myocytes in the distal compartment of the MFC were acquired $7 \mathrm{~d}$ after coculturing. Imaging was performed under bright-field conditions at a rate of $\sim 33$ fps while using a $20 \times$ objective. A myocyte contraction plot was then profiled using an image-based method previously described (Zahavi et al., 2015; Ionescu et al., 2016). Briefly, only myocytes that came in contact with axons were plotted. Time-lapse images were taken for analysis using ImageJ. To create a time trace of contractions, high contrast (bright or dark) ROIs were selected on each myotube. Movement of the selected spot due to myotube contraction was assessed by the change in the ROI intensity over time. The number of strong contractions, as measured from the time trace, was manually validated by reexamining the time-lapse image series. The number of strong and weak contractions in innervated myotubes was compared before and after $1 \mu \mathrm{M}$ TTX was added to the neuronal compartment. A myotube with a post- to pre-TTX difference of $>50 \%$ was measured as an increase or decrease in contraction, and the fraction of increased, decreased, and unchanged myotubes was calculated.

Immunostaining of cell cultures. Cultures were fixed in 4\% PFA and permeabilized with $0.1 \%$ Triton X-100, 5\% DS (Donkey Serum), 1 $\mathrm{mg} / \mathrm{ml}$ BSA in PBS. Samples were blocked for $1 \mathrm{~h}$ with blocking medium containing $5 \%$ DS, $1 \mathrm{mg} / \mathrm{ml}$ BSA in PBS. Primary antibodies against NFH (1:500), NRP1 (1:100), Sema3A (1:100), NRP2 (1:100), Sema3B (1:100), and acetylated tubulin (1:1000), ryanodine receptor 1 (Millipore, AB9078; 1:500), $\alpha$-actinin (Sigma-Aldrich, A5044; 1:400), Tau5 (Abcam, ab80579; 1:500) MAP2 (Millipore, ab5622; 1:500) were diluted in blocking solution and incubated overnight at $4^{\circ} \mathrm{C}$. Samples were incubated with species-specific fluorescent secondary antibodies for $2 \mathrm{~h}$ at room temperature. DAPI was used for visualizing nuclei in myotubes. In MFC, after the staining protocol was completed, the MFC was peeled from the dish by gently pulling it from the proximal to the distal side. ProLong mounting medium was added, and samples were covered with a \#1.5, $18 \times 18 \mathrm{~mm}$ coverslide.

RNA extraction and cDNA synthesis. Muscle tissues were immediately frozen with liquid nitrogen. Tissue was ground to powder using a pestle and mortar. Then $700 \mu$ l of TriReagent (Sigma-Aldrich) was added to the muscle powder, and the samples were further passed through a $21 \mathrm{G}$ needle 3 times for better homogenization. RNA from the TriReagentrinsed samples was further isolated following the TriReagent protocol. RNA quality was measured using NanoDrop3000 and a bio-analyzer. RNA purification of MN mass culture, along with transfected HeLa cells, was performed using TriReagent protocol as well. mRNAs were pooled in equal amounts and reverse-transcribed into double-stranded cDNA by using the SuperScript2 kit (QIAGEN).

NanoString Chip. A total of 100 ng RNA samples were outsourced to NanoString Technologies' facilities for an miR-Chip array assay of $\sim 800$ known miRs (NanoString Technologies). miR was quantified automatically by NanoString Technologies' instrumentation for miRs, which was hybridized with the template. Output data were analyzed by the 
Table 1. Primer design

\begin{tabular}{lll}
\hline Gene & Forward primer & Reverse primer \\
\hline hHPRT & GAACCAGGTTATGACCTTGATTTAT & GCAAGACGTTCAGTCCTGT \\
hSema3A & GCTCCAGTTATCATACCTTCCTTTTG & ACTGGCCACACAATCTTTTGAA \\
hNRP1 & ACCTGTTCTCTTTCAGGGAA & CAAGTTGCAGGCTTGATTCG \\
hB2M & CCGTGGAACCATGTGACTT & GGCATCTTCAAACCTCCATGA \\
hNRP2 & GAGGCCAACCAGACCCA & CGTAAACAATCCACTCGCAGTT \\
hSema3B & TCTCCTTCCAAGTCCA & CTCGGCACCCACAAACA \\
mSema3A & CACTGGGATGCCTGTCTT & GGCCAAGCCATTAAAAGTGA \\
mGFP & GCTACCCCGACCACATGAAGCA & GTCTTGTAGGTGCCGTCGTCCTTG \\
m-miR126 & ID000451 (Thermo Fisher Scientific) & ID000451 (Thermo Fisher Scientific)
\end{tabular}

$h$, Human gene; $m$, murine gene.

nCounter analysis system. All miRs were normalized to the 100 most abundant miRs in the samples.

Primer design. Based on the consensus sequences of the desired transcripts, 2 sets of primers were designed for each gene (Table 1).

qPCR for mRNA detection. qPCR was performed on the StepOne system (Invitrogen) in a $10 \mu \mathrm{l}$ reaction containing $4 \mu \mathrm{l}$ of RNA (20 ng), $5 \mu \mathrm{l}$ Syber green master mix (Thermo Fisher Scientific), and $1 \mu$ l of reverse and forward primers.

$m i R$ vectors and transfection. Mammalian expression vector $\mathrm{pMSCV}$ Blast-miR constructs were generously provided by Eran Hornstein (Weizmann Institute of Science). Mammalian expression vector of C9orft72 Di-peptide $\mathrm{PR}_{50}$ and $\mathrm{GR}_{50}$ constructs was generously provided by David Trotti (Jefferson University) (Wen et al., 2014). Next, 50,000 $\mathrm{HeLa} / \mathrm{U} 87$ human glioblastoma/muscles cells were plated in rich DMEM (1\% PS, 1\% GlutaMAX, 20\% FBS). After $24 \mathrm{~h}$, the culture medium was replaced with serum-free medium (Opti-MEM), and cells were transfected using FuGene NE 6 (Promega) protocol. Cells were collected after $48 \mathrm{~h}$ and used either for a functional assay or for RNA/protein extracts. Myocyte cultures were transfected using the same approach.

Semaphorin preparation. HEK293T cells were stably transfected to overexpress either Sema3A or an empty control. CM from 80\% confluent cultures were collected after $3 \mathrm{~d}$. We validated the purity level of the collected media using Coomassie staining and identified the stained band with a specific antibody against the desired protein using Western blot analysis.

NRP1 antibody application. A total of $5 \mu \mathrm{g} / \mathrm{ml}$ NRP1 antibody (R\&D System, AF566 dot ETH0915031) for the extracellular domain was added to the distal compartment of the MFC while maintaining a proximal-todistal volume gradient.

Histology tissue collection and fixation. GC muscles of 20 samples were harvested and fixed in 4\% PFA. The samples were then outsourced for a histological assessment at Patho-Logica. All tissues were trimmed into block cassettes and sent to CDX Diagnostics for slide preparation.

Slide preparation and histological evaluation. Tissues were trimmed, embedded in paraffin sections at no more than $5 \mu \mathrm{m}$ thickness, and stained with H\&E. The mean minimal muscle fiber diameter thickness was measured in microns by performing a manual count using a $10 \times$ lens and analyzed by expert pathologist.

$x$ CELLigence impedance measurement. For each experiment, 30,000 U87 cells were plated with rich DMEM in E-Plate L8 wells and incubated together with the xCELLigence system (ACEA Biosciences) at $37^{\circ} \mathrm{C}, 5 \%$ $\mathrm{CO}_{2}$ overnight. Impedance data were collected at $5 \mathrm{~min}$ intervals. After 24 h, poor DMEM (1\% PS, 1\% GlutaMAX) with Sema3A or its control medium was replaced and recording proceeded. The data were analyzed using RTCA data analysis software 1.0 and normalized to the control sample.

CatWalk XT gait analysis. The CatWalk is a video-based analysis system used to assess gait in voluntarily walking mice (Noldus Information Technology). The principle of this method is based on an optical technique. The light of a fluorescence tube is completely internally reflected on a glass walkway floor. When the animal crosses the walkway, the light leaves the glass and illuminates only the area of contact. In this way, the different paw contacts are visualized. Based on position, pressure, and the surface area of each foot paw, multiple parameters are calculated.
Only compliant and continuing trials for each animal were analyzed, averaged, and the mean was calculated.

Experimental design and statistical analysis. Data are mean \pm SEM. The statistical analysis was assessed by Student's $t$ test. In all cases, differences were considered to be statistically significant if $p<0.05$

\section{Results}

Sema3A and NRP1 levels are elevated in muscles and the MNs of ALS models

ALS disease is considered to be a distal axonopathy involving axon degeneration and NMJ disruption as key processes in its pathology (Fischer et al., 2004). We therefore hypothesized that destabilizing factors secreted from adult presymptomatic ALS mutant muscles might be involved in triggering axon degeneration of MNs. Because Sema3A is known to act in such a manner, at least in development, and it was already reported to be elevated in ALS, we decided to focus on this factor (De Winter et al., 2006; Körner et al., 2016). Following this hypothesis, we first examined the expression of Sema3A in SOD $1^{G 93 A}$ GC muscles in comparison with that of their LMs; (Fig. 1A,B; Fig. 1-1, available at https://doi.org/10.1523/JNEUROSCI.3037-17.2018.f1-1). Western blot analysis of muscle protein extracts revealed significant elevations in Sema3A protein levels in muscles of presymptomatic SOD $1^{G 93 A}$ mice as early as P30 and P60, whereas testing Sema3A levels in younger animals (P7) showed no apparent differences compared with their LM controls (mean fold change over LM: P30 SOD1 ${ }^{\text {G93A }}, 3.08 \pm 0.86$; P30 LM, $1 \pm 0.36$; P60 $S O D 1^{G 93 A}, 2.2 \pm 0.45 ; \mathrm{P} 60 \mathrm{LM}, 1 \pm 0.32$; 7 SOD $1^{G 93 A}, 1.2 \pm 0.7$; $\mathrm{P} 7 \mathrm{LM}, 1 \pm 0.42)$. To validate this difference, we also tested the transcript levels of Sema3A (Fig. 1C). qPCR analysis of total RNA extracts from muscles at presymptomatic SOD $1^{G 93 A}$ stage and LM mice identified an $\sim 1$.7-fold increase in Sema3A mRNA of $S O D 1^{G 93 A}$ muscles (mean fold change over LM: SOD $1^{\text {G93A, }}$ $1.72 \pm 0.32$; LM, $1 \pm 0.06$ ). Because GC muscle tissues contain heterogeneous cell types and to verify that the levels of Sema3A are indeed higher specifically in $S O D 1^{G 93 A}$ muscles fibers, we immunostained primary myocyte cultures from P60 SOD $1^{\text {G93A }}$ and LM mice for Sema3A (Fig. 1D,E). Quantifying the mean intensity values showed a significant $50 \%$ increase in the $S O D 1^{G 93 A}$ myocytes (a mean fold change in intensity over LM: $\left.S O D 1^{G 93 A}, 1.5 \pm 0.06 ; \mathrm{LM}, 1 \pm 0.04\right)$. We also collected CM from myocyte cultures to determine whether the increase in Sema3A protein also results in an increase in its secretion (Fig. $1 F$ ). Western blot analysis indicated that Sema3A levels were also elevated in P60 SOD $1^{\text {G93A }}$ myocyte-CM (a mean fold change over LM: $\left.S O D 1^{G 93 A}, 2.3 \pm 0.55 ; \mathrm{LM}, 1 \pm 0.08\right)$. Because NMJ disruption is a primary event in ALS, we sought to examine the levels of Sema3A in NMJ in vivo (Fig. $1 G, H$ ). Immunostaining for Sema3A in GC muscles showed a sixfold increase in the number of muscle fibers expressing Sema3A in their NMJs. Whereas only $\sim 5 \%$ of NMJs stained positively for Sema3A in LM muscles, we identified its expression in $\sim 30 \%$ of NMJs in P60 SOD $1^{\text {G93A }}$ mice (the mean percentage of NMJs expressing Sema3A: SOD ${ }^{\text {G93A }}$, $30.83 \pm 4.73 \%$; LM, $4.56 \pm 2.4 \%$ ). Interestingly, a previous study described Sema3A elevation in SOD ${ }^{\text {G93A }}$ mice specifically in fast fatigue NMJs expressing myosin-IIb marker (De Winter et al., 2006). Because fast fatigue NMJs are the first to become disrupted and be eliminated in ALS pathology, we examined Sema3A levels both at P90 and P120 and hypothesized that Sema3A levels will eventually drop in later stages of the disease. We found that whereas the percentage of NMJs expressing Sema3A in SOD ${ }^{\text {G93A }}$ in P90 animals is similar to P60, the end-stage animals (P120) were shown to display a reduction in Sema3A-positive NMJs, and 


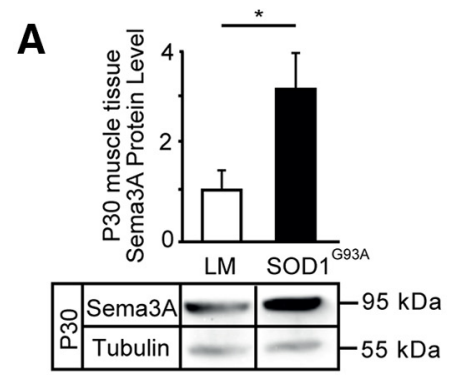

D
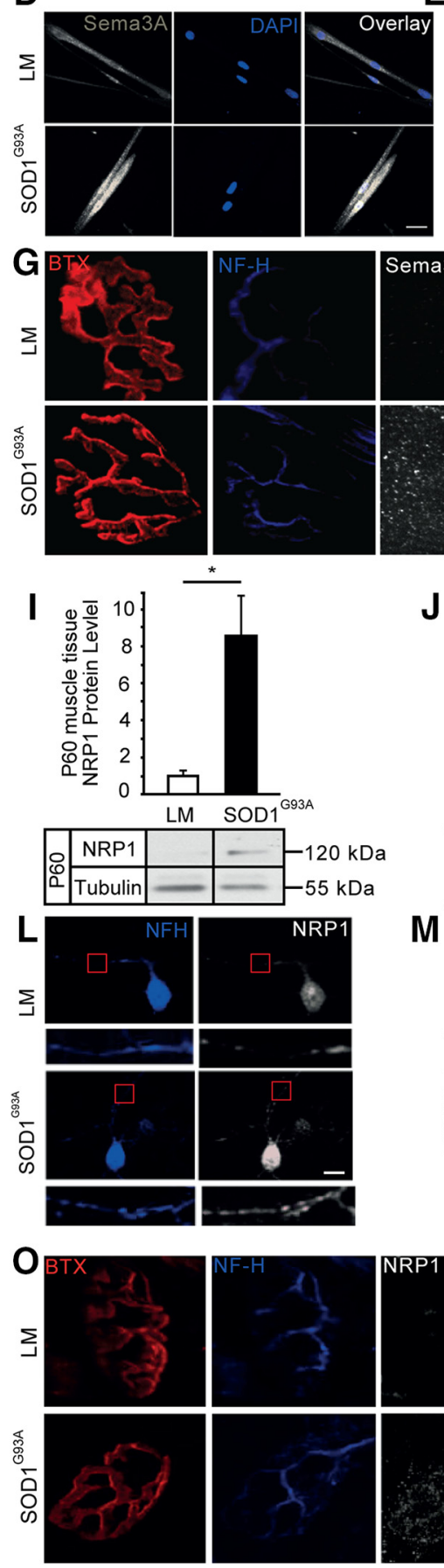
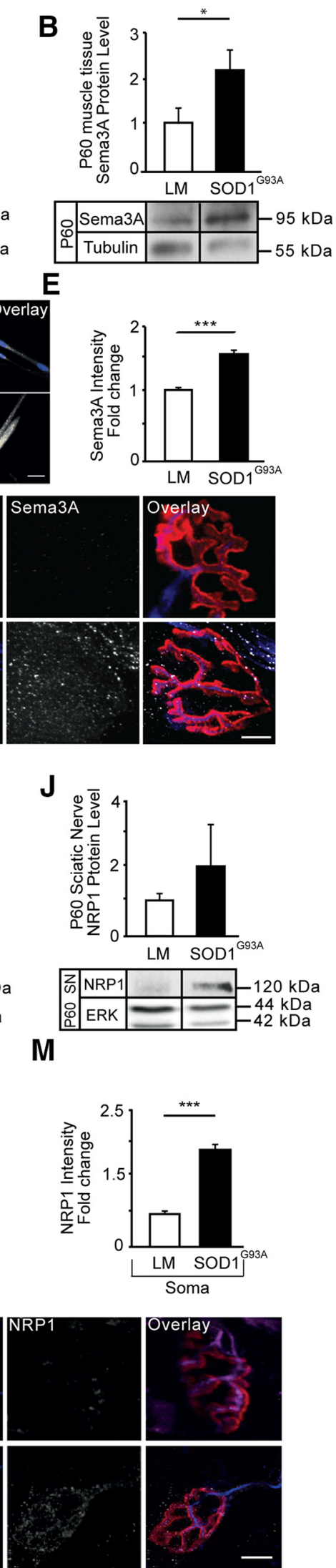

E

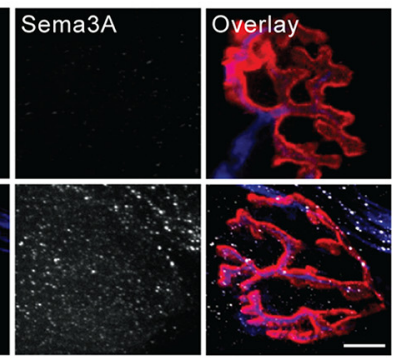

J
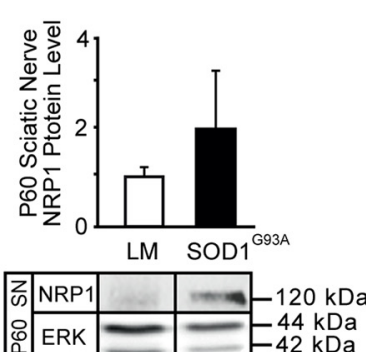

M
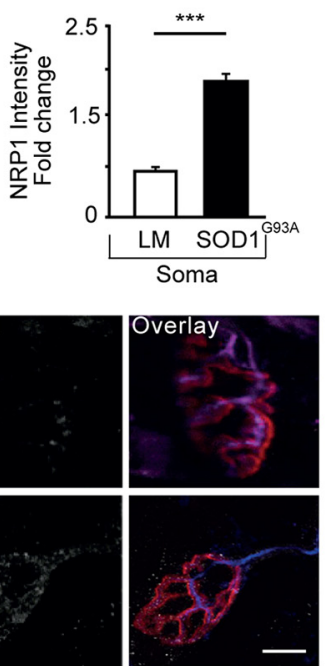
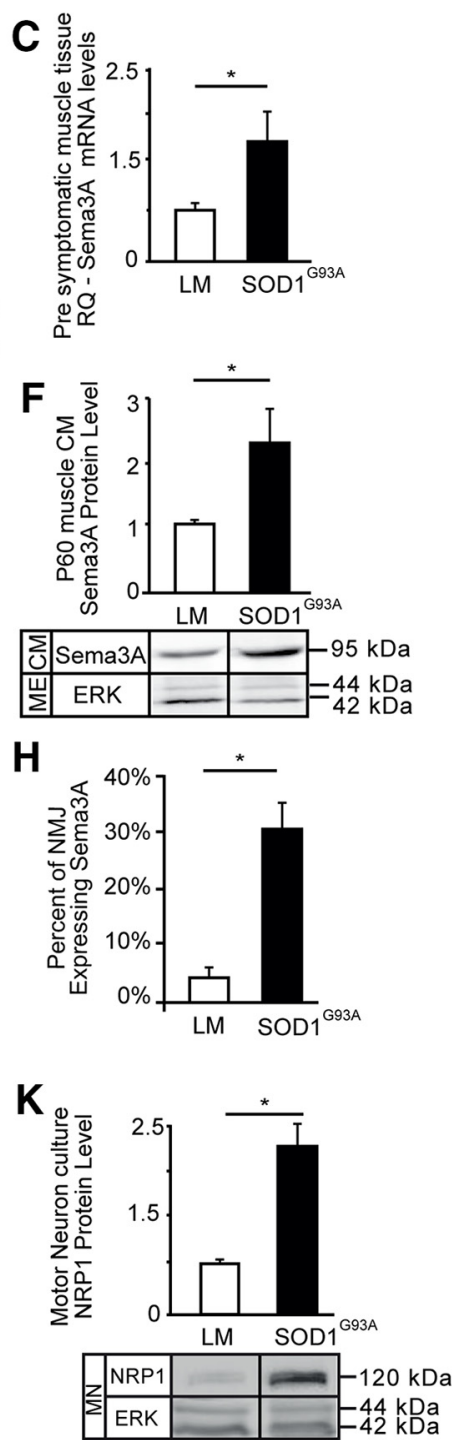

N

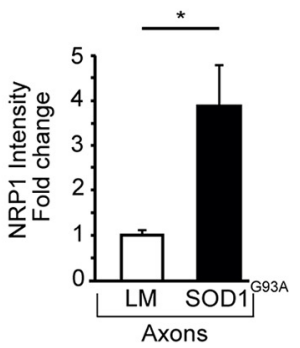

P

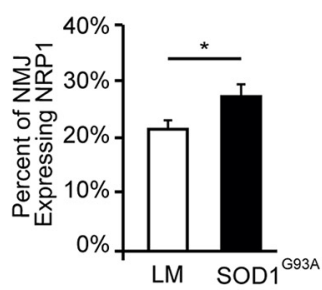

Figure 1. Presymptomatic elevation in the levels of Sema3A and NRP1 in ALS models. $\boldsymbol{A}, \boldsymbol{B}$, Western blot analysis of P30 and P60 GC muscle extracts revealed that the levels of Sema3A are elevated in presymptomatic SOD $1^{G 93 A}$ muscles compared with their corresponding LM control wherein at earlier stages we found no significant difference (Figure 1-1, available at https://doi.org/10.1523/ JNEUROSCI.3037-17.2018.f1-1). Tubulin was used as a loading control. P30 (Student's $t$ test, $n=3,{ }^{*} p=0.042$ ). P60 (Student's $t$ test, $n=4,{ }^{*} p=0.038$ ). $C$, qPCR analysis of presymptomatic P60 and P30 GC muscle extracts also shows an elevation in the mRNA levels of Sema3A in SOD $1^{G 93 A}$ (Student's t test, SOD ${ }^{693 A}, n=5, \mathrm{LM}, n=4,{ }^{*} p=0.049$ ). D, Immunostaining of primary myocytes after $7 \mathrm{~d}$ in culture shows elevated levels of Sema3A in primary myocytes of SOD ${ }^{G 93 A}$. White represents Sema3A. Blue represents nuclear DAPI staining. Scale bars, (Figure legend continues.) 
no apparent difference existed between WT and SOD1 ${ }^{G 93 A}$ mice (Fig. 1-2A,B, available at https://doi.org/10.1523/JNEUROSCI. 3037-17.2018.f1-2). Together, these results indicate that a significant part of the MN population is exposed to high levels of Sema3 A in presymptomatic stages and that this specific population is disrupted and eliminated during disease progression. We then proceeded to investigate the expression of the Sema3Areceptor binding unit, NRP1, in ALS (Fig. 1I). Western blot analysis of GC muscle extracts revealed a significant $\sim 8$-fold increase in NRP1 (the mean fold change over LM: SOD1 ${ }^{G 93 A}, 8.6 \pm 2.2$; $\mathrm{LM}, 1 \pm 0.3$ ). Because MNs are a primary target in ALS, we wanted to determine whether NRP1 is also overexpressed in the MNs of $S O D 1^{G 93 A}$ mice. First, we performed Western blot analysis of SNs and observed an $\sim 2$-fold elevation in NRP1 levels of P60 SOD $1^{\text {G93A }}$ mice (Fig. 1J; the mean fold change over LM: $\left.S O D 1^{G 93 A}, 1.96 \pm 1.22 ; \mathrm{LM}, 1 \pm 0.21\right)$. Next, we obtained protein extracts of primary MN cultures for Western blot analysis and confirmed an $\sim 2.5$-fold elevation in NRP1 levels in the MNs of $S O D 1^{G 93 A}$ culture (Fig. $1 K$; the mean fold change over LM: $S O D 1^{G 93 A}, 2.3 \pm 0.16$; LM, $\left.1 \pm 0.06\right)$. Immunostaining of primary MN cultures for NRP1 resulted in analogous findings (Fig. $1 L-N)$. Intriguingly, the NRP1 signal in $S O D 1^{G 93 A}$ is generally higher than in LM and is increased even more in axons compared with cell bodies (the mean fold change over LM: SOD $1^{\text {G93A }}$ soma, $1.86 \pm 0.13 ; \mathrm{LM}$ soma, $1 \pm 0.05 ; S O D 1^{G 93 A}$ axon, $3.83 \pm 0.95 ; \mathrm{LM}$ axon, $1 \pm 0.11)$. Finally, immunostaining for NRP1 in GC muscles confirmed a similar shift of $\sim 30 \%$ in the number of NMJs expressing NRP1, as we had observed for Sema3A in SOD1 $1^{\text {G93A }}$ mice, both at P60 and P90. However, also this time, the differences were abolished in the end stages of the disease (P120) (Fig. $1 O, P$; Fig. 1-2C,D, available at https://doi.org/10.1523/JNEUROSCI.3037-17.2018.f1-2; the mean percentage of NMJs expressing

$\leftarrow$

(Figure legend continued.) $5 \mu \mathrm{m} . \boldsymbol{E}$, Image analysis reveals an increase in Sema3A intensity in SOD $1^{G 93 A}$ primary myocytes (Student's $t$ test, $n=3, \sim 80$ cells, ${ }^{* * *} p=0.00001$ ). $F$, Western blot analysis of primary myocyte-CM revealed a higher level of Sema3A in the CM of SOD $1^{693 A}$. Cultures were lysed after $\mathrm{CM}$ collection, and equal loading volumes of lysates were immunoblotted for ERK to validate CM, which was produced from a similar mass of myocytes (Student's $t$ test, $\left.n=3,{ }^{*} p=0.018\right) . \mathbf{G}, \boldsymbol{H}$, Immunostaining of fixed whole P60 $\mathrm{GC}$ muscles shows distinct Sema3A expression in the NMJs of SOD $7^{693 A}$ mice. White represents Sema3A. Red represents TMR-BTX labeling of acetylcholine receptors on postsynapse. Blue represents presynaptic NFH in neurons. The percentage of muscle fibers expressing Sema3A in their NMJs in P60 SOD $1^{693 A}$ mice is higher ( $\sim 100$ NMJ per 1 biological repeat; Student's $t$ test, SOD ${ }^{693 A}, n=4$; WT, $n=$ $\left.3 ;{ }^{*} p=0.011\right)$. Scale bars, $10 \mu \mathrm{m}$. We also examined Sema3A expression in later stages of the disease (Figure 1-2, available at https://doi.org/10.1523/JNEUROSCI.3037-17.2018.f1-2). $I$, Western blot analysis of $\mathrm{GC}$ muscle extracts from P60 mice revealed elevated NRP1 levels in the muscles of $S 0 D 11^{G 93 A}$. Tubulin was used as a loading control (Student's $t$ test, $n=3,{ }^{*} p=$ 0.048). J, Western blot analysis of SN extract from P60 mice shows an elevation in the levels of NRP1 in the SNs of SOD $1^{693 A}$ mice $(n=3)$. $\boldsymbol{K}$, Western blot analysis of primary MN lysates after $3 \mathrm{~d}$ in culture reveals an elevation in the NRP1 levels in SOD $1^{693 A} \mathrm{MNs}$, which are not regulated by Sema3A binding (Figure 1-3, available at https://doi.org/10.1523/JNEUROSCI.303717.2018.f1-3). ERK was used as a loading control (Student's $t$ test, $n=3,{ }^{*} p=0.031$ ). $\mathbf{L}-\mathbf{N}$, Immunostaining of primary MNs after $3 \mathrm{~d}$ in culture shows an elevation in the levels of NRP1 in both axons (inset, $\sim 4.1$-fold) and somata ( $\sim 1.9$-fold) of $S O D 1^{693 A}$ MNs. White represents NRP1. Blue represents NFH. Somata (Student's test, $n=3, \sim 40$ cells, ${ }^{* * *} p=0.00021$ ); axons (Student's $t$ test, $n=3, \sim 40$ cells, ${ }^{*} p=0.012$ ). Scale bars, $10 \mu \mathrm{m} . \mathbf{0}, \boldsymbol{P}$, Immunostaining of fixed whole P60 GC muscles shows distinct NRP1 expression in the NMJs of SOD1 ${ }^{G 93 A}$ mice. White represents NRP1. Red represents BTX. Blue represents NFH. The percentage of muscle fibers expressing NRP1 in their NMJs in P60 SOD $1^{\text {G93A }}$ mice is higher (Student's $t$ test, SOD $1^{693 A}$, $n=4 ; \mathrm{WT}, n=3 ;{ }^{*} p=0.042$ ). Scale bars, $5 \mu \mathrm{m}$. We further examined NRP1 expression in later stages of the disease (Figure 1-2, available at https://doi.org/10.1523/JNEUROSCI.303717.2018.f1-2). Elevations in Sema3A and its coreceptor were found also in human sALS samples (Figure 1-4, available at https://doi.org/10.1523/JNEUROSCI.3037-17.2018.f1-4). A-C, E, F, $I-K, M, N$, Data represent the mean fold difference over the LM control \pm SEM.
NRP1: P60: SOD1 ${ }^{\text {G93A }}, 27.5 \pm 2.04 \%$; LM, $\left.21.27 \pm 1.22 \%\right)$. To determine whether the elevated NRP1 levels result from feedback due to an increase in its ligand, we treated primary $\mathrm{MN}$ cultures from LM embryos with soluble Sema3A for $3 \mathrm{~d}$ and performed Western blot analysis on cell culture lysates. Importantly, we did not observe any difference in NRP1 expression after applying Sema3A, suggesting that NRP1 levels are regulated by an intrinsic mechanism in MNs (Fig. 1-3, available at https://doi.org/ 10.1523/JNEUROSCI.3037-17.2018.f1-3). Finally, to validate our finding with other ALS models and to emphasize the impact of Sema3A in ALS, we performed Western blot analysis for Sema3A and NRP1 expression in human mesenchymal stem cells from sporadic ALS patients and healthy controls, as well as in myocyteexpressing C9orf72-PR 50 and their CM for Sema3A. In addition, we compared the results with those of a mock control. Remarkably, in all of these ALS models, we identified high expression of Sema3A and NRP1 (Fig. 1-4, available at https://doi.org/10.1523/JNEUROSCI. 3037-17.2018.f1-4).

Together, our combined in vivo and in vitro data suggest that the levels of both Sema3A and its cobinding receptor, NRP1, are presymptomatically increased in several ALS models as well as in sALS patients. These findings suggest that the Sema3A pathway is a common denominator in various ALS mutations; thus, it may contribute to $\mathrm{MN}$ degeneration in ALS.

\section{Application of Sema3A on wild-type MN axons results in axon degeneration}

Because our findings suggest that Sema3A is produced and secreted in excess from muscles of ALS models, and because muscles interact specifically with $\mathrm{MN}$ axons, we sought to test the activity of Sema3A exclusively in this distal subcellular compartment. To this end, we used an MFC that allows precise control, monitoring, and manipulation of subcellular microenvironments (Fig. 2-1, available at https://doi.org/10.1523/JNEUROSCI.303717.2018.f2-1) (Zahavi et al., 2015). We cultured healthy ventral SC explants from transgenic mouse embryos expressing GFP under the MN-specific promoter HB9 (HB9::GFP) in one compartment of the MFC and enabled axons to extend into the opposing compartment, thus segregating axons and cell bodies into two isolated compartments. To verify that our MFCs can efficiently segregate $\mathrm{MN}$ axons from their somata, we stained the neuronal culture in the MFC system for the dendritic and axonal markers MAP2 and Tau, respectively (Fig. 2-1, available at https://doi.org/ 10.1523/JNEUROSCI.3037-17.2018.f2-1). We confirmed that all neurites that traversed the distal compartment are positive for Tau staining and negative for MAP2. Next, we purified Sema3A or control media as described previously (Ben-Zvi et al., 2006), and applied them to the distal compartment, while imaging the axons for $16 \mathrm{~h}$ (Fig. 2A). Our recordings reveal extensive axon degeneration in the Sema3A-treated MFCs 6-8 h after its application (Fig. 2B; Movies 1, 2; the mean percentage of degenerated axons: Sema3A, $83.01 \pm 3.54 \%$; control, $23.94 \pm 7.6 \%$ ). Coapplication of NRP1-blocking antibody and Sema3A on MN axons inhibits the Sema3A-dependent axon degeneration (Fig. 2B; the mean percentage of degenerated axons: Sema3A and NRP1 antibody, $25.00 \pm 12 \%)$. These data indicate that Sema3A can trigger axon degeneration in MNs when applied exclusively on distal axons, and further support our hypothesis that an increase in muscle-derived Sema3A might contribute to axon degeneration in ALS. 
A

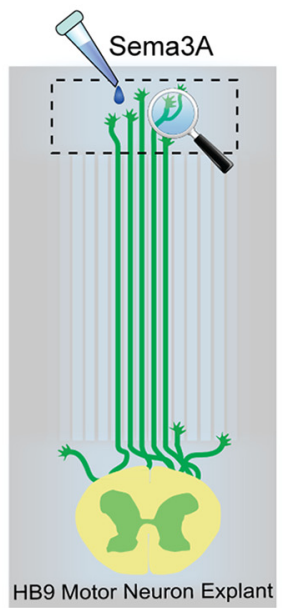

C

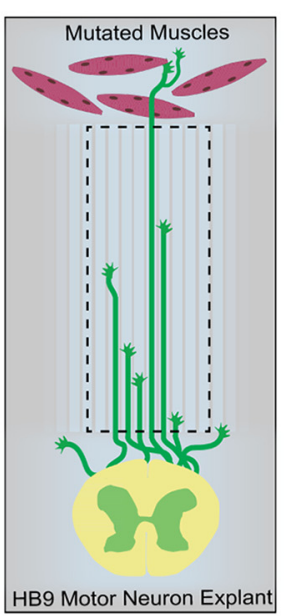

$\mathbf{F}$

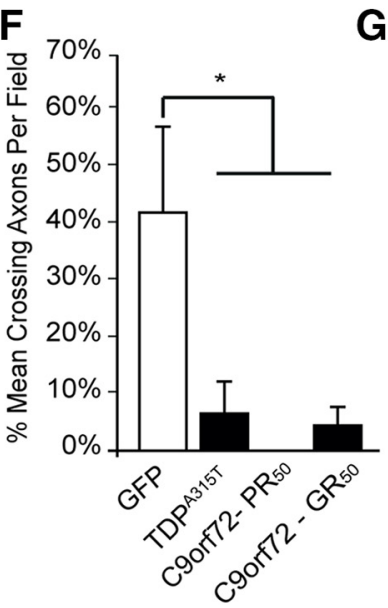

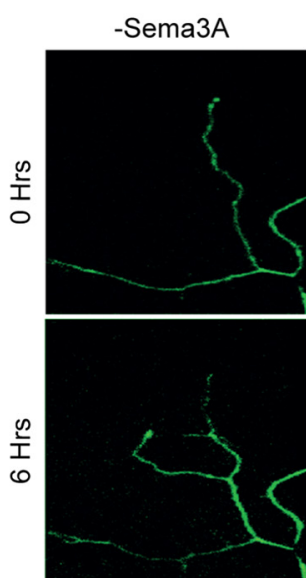

D
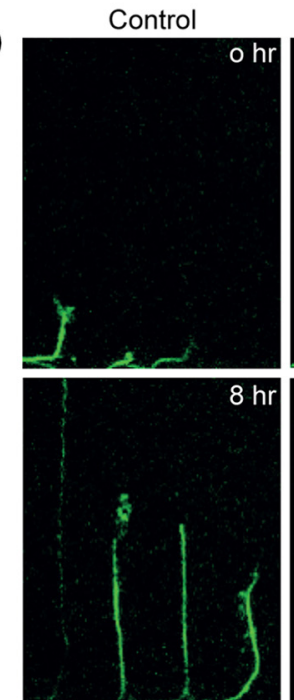

G

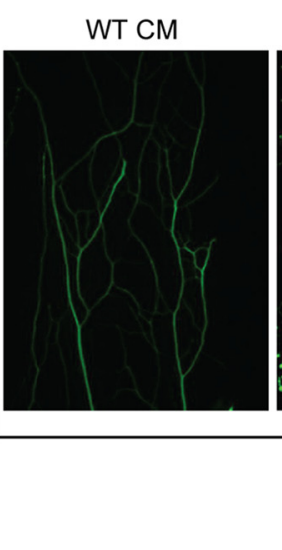

B

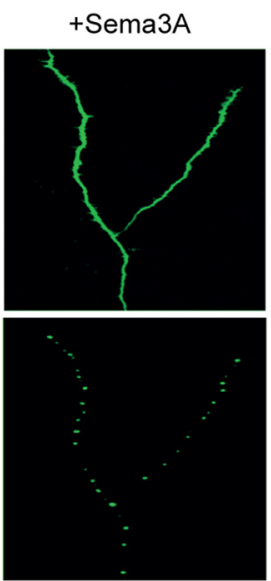

NRP1ab +Sema3A
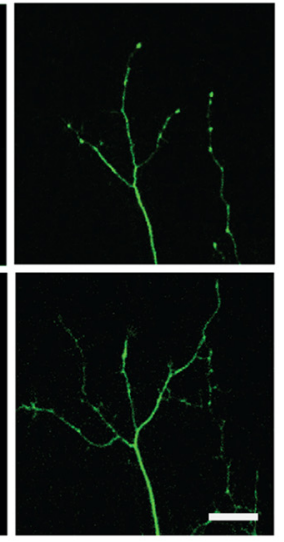

SOD 1 G93A

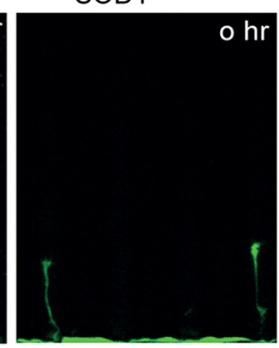

SOD1 $1^{\text {G93A }+N R P 1 ~ a b ~}$

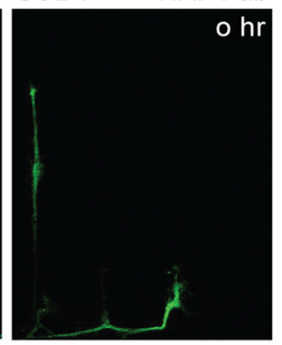

E
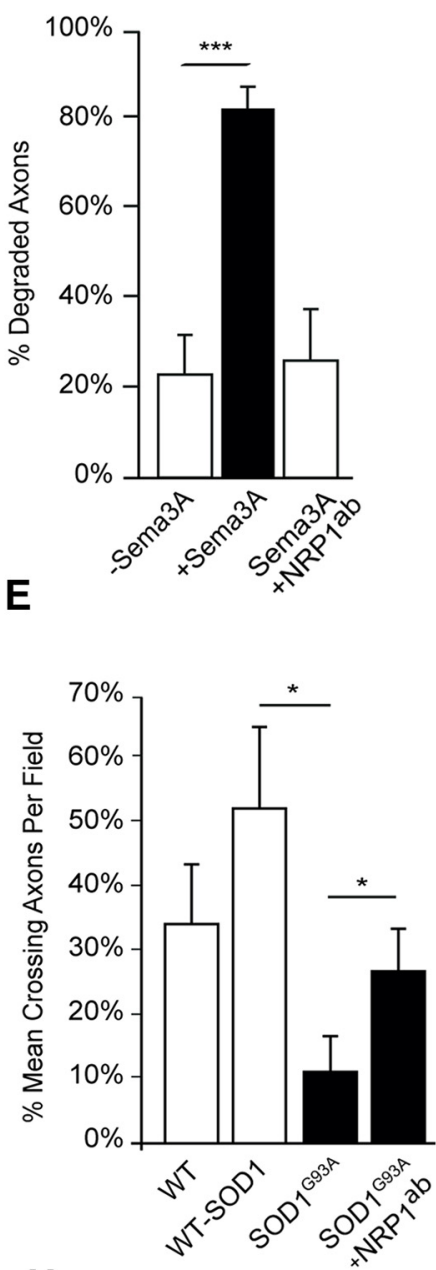

H
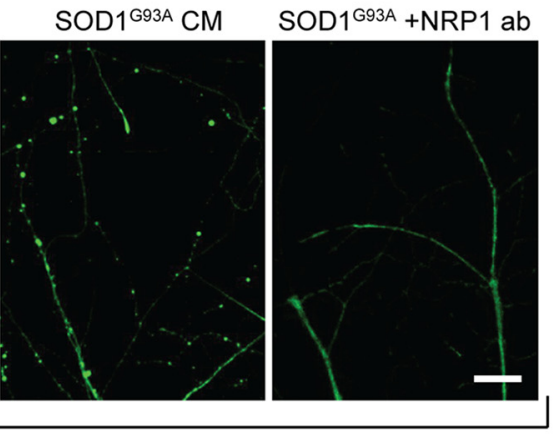

SOD1 ${ }^{\mathrm{G} 3 \mathrm{~A} A}$ Axons

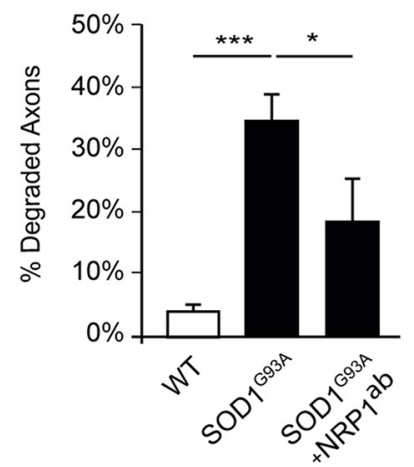

Figure 2. Sema3A as well as primary myocytes expressing diverse ALS-causing mutations impair the growth of wild-type HB9::GFP motor axons and enhance their retraction and degeneration. A, Experimental procedure illustration and representative time-lapse images of HB9::GFP motor axons (Figure 2-1, available at https://doi.org/10.1523/JNEUROSCI.3037-17.2018.f2-1) in the distal compartment of an MFC with no muscles after applying Sema $3 \mathrm{~A}$ to the distal compartment. After $6 \mathrm{~h}$, axons in the distal compartment of chambers that were treated with Sema3A undergo degeneration, whereas axons in the control chamber or axons cotreated with NRP1 antibody and Sema3A continue growing. Scale bar, $20 \mu \mathrm{m}$. $\boldsymbol{B}$, Quantification of the rate of degraded axons in the distal compartment revealed a higher percentage of degradation in chambers that were exposed to Sema3A compared with either control or coapplication of Sema3A and NRP1 antibody ( $\sim 60$ axons for Sema3A treatment, $\sim 70$ axons for Control; Student's $t$ test; $n=4$; mean \pm SEM, $\left.{ }^{* * *} p=0.00022\right)$. C, Schematic view of the experimental procedure in D-F. HB9\%:GFP SC explants and

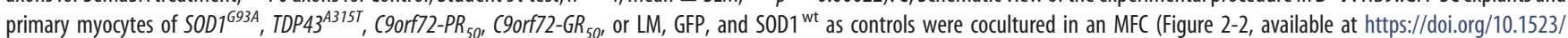
JNEUROSCI.3037-17.2018.f2-2), and the growth of HB9::GFP axons was assessed by time-lapse imaging of the microgroove compartment. D, Representative time-lapse images of the HB9::GFP axon growth when cocultured with (left to right) $\mathrm{LM}, S O D 1^{G 93 A}$, and SOD $1^{G 93 A}+\mathrm{NRP} 1$ antibody. The presence of $S O D 1^{G 93 A}$ myocytes in the distal compartment triggers the retraction and degeneration of HB9::GFP motor axons growing in the groove compartment and prevents their traversing. When NRP1 antibody is applied to the distal compartment, together with SOD1 ${ }^{693 A}$-expressing myocytes, axons are less prone to degenerate. Scale bar, $5 \mu \mathrm{m}$. $\boldsymbol{E}$, Quantification of the rate of axons traversing the distal compartment in $\boldsymbol{B}$ shows the mean percentage of axons that traversed the distal compartment out of the total axons in each field ( $n=3$; NRP1 antibody experiment, $n=4$; Student's $t$ test, ${ }^{*} p=0.025,{ }^{*} p=0.0433$ ). F, Quantification of (Figure legend continues.) 


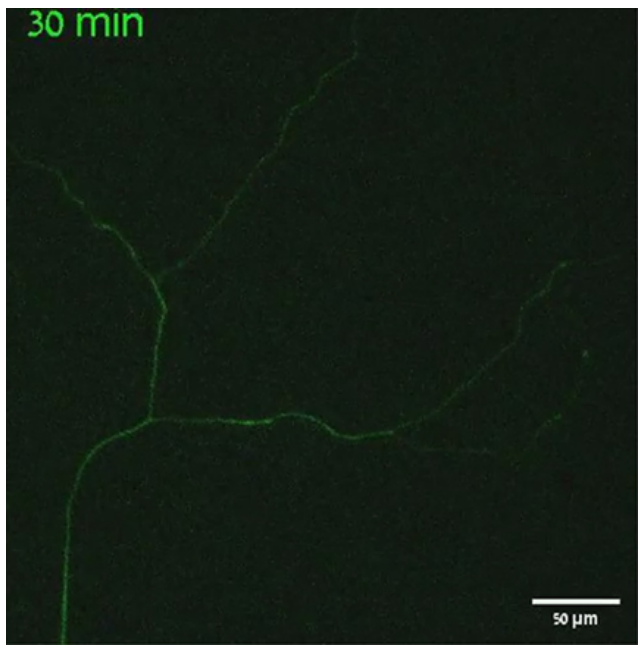

Movie 1. Sema3A control medium on HB9::GFP distal axons. Timelapse image series of HB9::GFP axons in the distal compartment of an MFC with control medium added to the distal compartment. Scale bar, $50 \mu \mathrm{m}$.

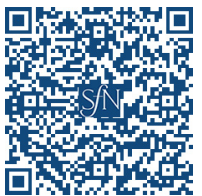

\section{Muscles expressing diverse ALS mutations initiate axon degeneration}

To study the molecular mechanisms enabling the communication between MNs and their environment, which are essential for cell survival and synapse maintenance, we extended the use of the MFC system to coculture primary MNs and primary myocytes (Ionescu et al., 2016). Briefly, ventral SC explants from healthy 12-day-old (E12) HB9::GFP embryos were cultured in the proximal compartment, in the presence or absence of primary myocytes extracted from adult mice in the distal compartment (Fig. 2-1, available at https://doi.org/10.1523/JNEUROSCI.303717.2018.f2-1). As we showed previously (Zahavi et al., 2015), culturing HB9::GFP explants in the presence of wild-type muscles facilitates the rapid and directed growth of axons into the distal compartment (Fig. 2-1, available at https://doi.org/ 10.1523/JNEUROSCI.3037-17.2018.f2-1), suggesting that muscles secrete factors that support and promote the growth of motor axons. However, because ALS-mutated muscles were found to have intrinsic abnormalities throughout disease progression

$\leftarrow$

(Figure legend continued.) the rate of axons traversing the distal compartment shows the mean percentage of axons that traversed the distal compartment out of the total number of

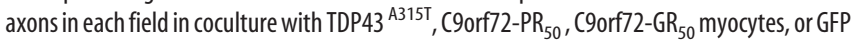
as a control. The traversing rate of HB9::GFP motor axons into the distal compartment in each of the cocultures with muscle-expressing ALS mutations is significantly reduced ( $n=3$; Student's $t$ test, $\left.\mathrm{GR}_{50},{ }^{*} p=0.0137 ; \mathrm{PR}_{50},{ }^{*} p=0.0374 ; \mathrm{TDP}^{*}{ }^{*} p=0.0304\right)$. G, Representative images of fixed and immunostained SOD $1^{693 A}$ motor axons in the distal compartment of an MFC after applying LM or SOD ${ }^{693 A}$ myocyte CM to the distal compartment. After $48 \mathrm{~h}$, axons in the distal compartment of chambers that were treated with $S O D 1^{693 A} \mathrm{CM}$ underwent degeneration, whereas axons that were treated with LM CM remained intact. WT MN axons remained intact after application of either CM (Figure 2-3, available at https://doi.org/10.1523/ JNEUROSCI.3037-17.2018.f2-3). When NRP1 antibody is applied to the distal compartment, together with $\mathrm{SOD}^{\mathrm{Gg}}{ }^{\mathrm{C} A} \mathrm{CM}$, axons are less prone to degenerate, suggesting the involvement of multiple factors (Figure 2-4, available at https://doi.org/10.1523/JNEUROSCI.3037-17.2018.f24). Green represents acetylated tubulin. Scale bar, $20 \mu \mathrm{m}$. $\boldsymbol{H}$, Quantification of the rate of degenerated $S O D 1^{G 93 A}$ axons in the distal compartment treated with control $C M, S O D 1^{693 A} C \mathrm{CM}$, or SOD $1^{693 A} \mathrm{CM}$ that was coincubated with anti-NRP1 antibody (Student's test; $n=3 ;{ }^{* * *} p=$ $\left.5 \times 10^{-7},{ }^{*} p=0.018\right) .{ }^{* *} p<0.01$

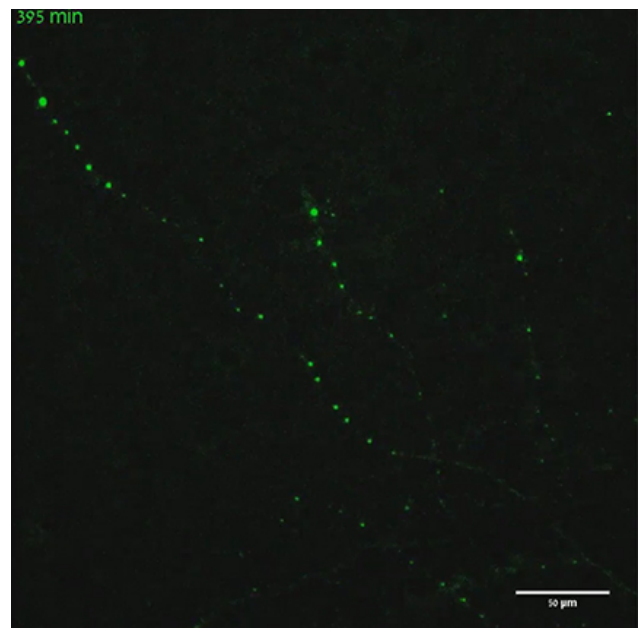

Movie 2. Sema $3 A$ in the distal compartment drives the degeneration of HB9::GFP distal axons. Time-lapse image series of HB9::GFP axons in the distal compartment of an MFC with Sema3A added to the distal compartment. Scale bar, $50 \mu \mathrm{m}$.
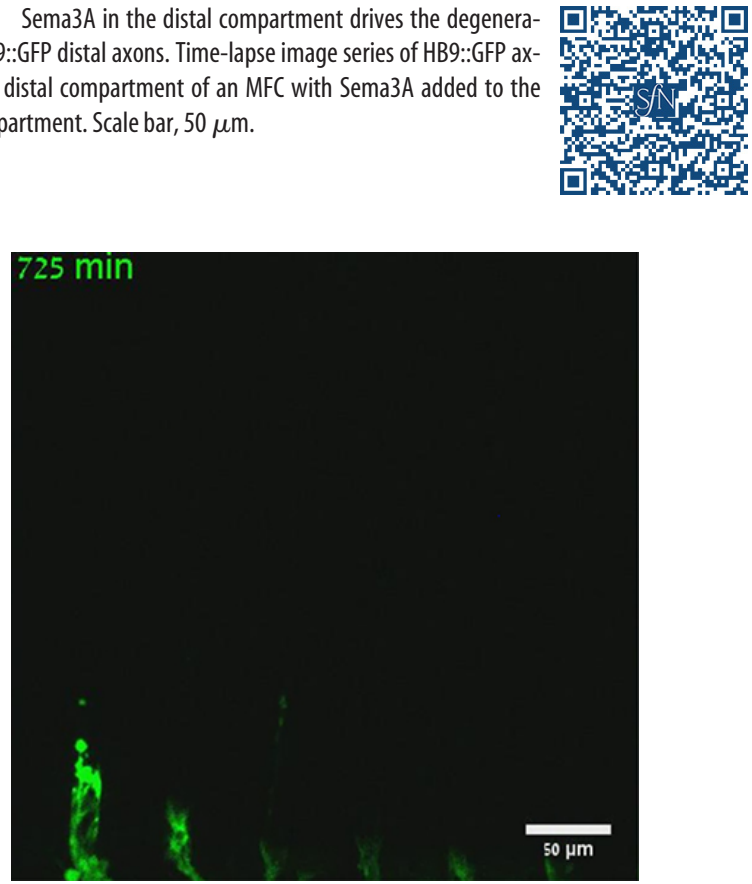

Movie 3. HB9::GFP axonal growth toward SOD1 $1^{693 A}$ myocytes. Time-lapse image series of HB9::GFP axons in the microgroove compartment of an MFC with SOD1 ${ }^{693 A}$ myocytes in the distal compartment (top). Scale bar, $50 \mu \mathrm{m}$.

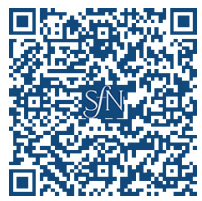

(Loeffler et al., 2016), we hypothesized that the nature of these factors will be altered. To study the effect of ALS muscles on MN axons in a simplified system, we plated primary myocytes from presymptomatic P60 SOD $1^{\text {G93A }}$ and LM mice as well as WT myocytes transfected to express SOD $1^{\mathrm{wt}}$ in the distal compartment. Myocyte cultures were allowed to fuse and differentiate. Importantly, in all the described cases, myocyte morphology, fusion, and differentiation parameters were similar, and the culture showed no apparent difference (Fig. 2-2, available at https:// doi.org/10.1523/JNEUROSCI.3037-17.2018.f2-2). After 7 d, HB9::GFP SC explants were cultured in the proximal compartment. Cocultures were incubated until the HB9::GFP axons began extending toward the microgroove compartment. Once the axons reached the microgroove compartment, the extension of HB9::GFP axons along the microgrooves was recorded for $16 \mathrm{~h}$ 


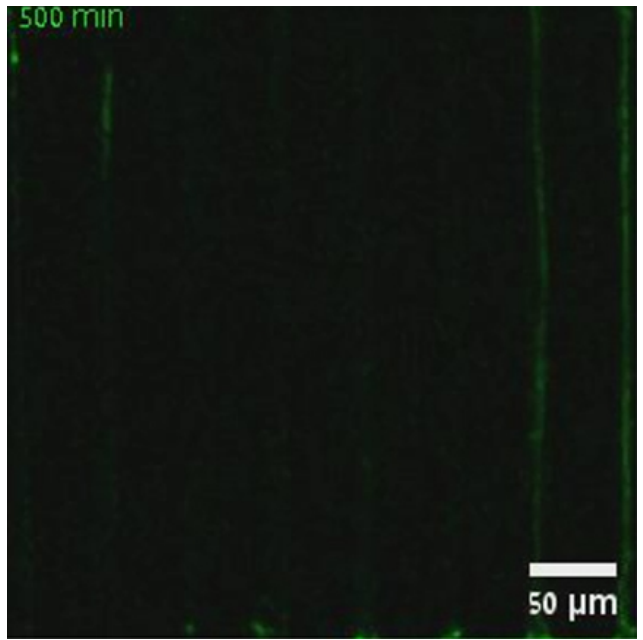

Movie 4. HB9::GFP axonal growth toward LM myocytes. Time-lapse image series of HB9::GFP axons in the microgroove compartment of an MFC with LM myocytes in the distal compartment (top). Scale bar $50 \mu \mathrm{m}$.

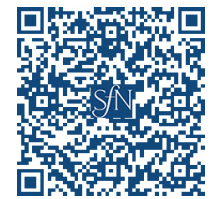

(Fig. 2C). Surprisingly, HB9::GFP axons that were cocultured with the SOD $1^{G 93 A}$ myocytes were less likely to traverse the distal side (Fig. $2 D, E$ ). During this period, axons extending toward the $S O D 1^{G 93 A}$ myocytes were markedly incapable of traversing the distal compartment and underwent retraction, degeneration, or remained static in place, compared with the LM and SOD $1^{\text {wt }}$ controls (Fig. 2D; Movies 3,4). Noteworthy, the addition of NRP1-blocking antibodies to the distal compartment, targeting Sema3A binding to the extracellular site of NRP1, improved the traversing rate of axons (Fig. $2 E$; the mean axon traversal rate per field: $\mathrm{LM}, 33.88 \pm 10.40 \%$; SOD1 $1^{\mathrm{wt}}, 52.66 \pm 12.7 \% \mathrm{SOD}^{\mathrm{G} 93 \mathrm{~A}}$, $11.1 \pm 5.5 \%$; SOD $\left.1^{\mathrm{G} 93 \mathrm{~A}+\mathrm{NRP} 1-\mathrm{ab}}, 28.18 \pm 5.4 \%\right)$. We further transfected primary myocyte cultures with several more ALSlinked mutations or aberrant toxic proteins as follows: C9orf72$\mathrm{PR}_{50}$, C9orf72-GR 50 (Wen et al., 2014), and TDP43 ${ }^{\mathrm{A3} 15 \mathrm{~T}}$ and used empty-GFP vector as a control. Transfected myocytes exhibit normal morphology and fusion in comparison with the WT muscle culture in our system (Fig. 2-2, available at https:// doi.org/10.1523/JNEUROSCI.3037-17.2018.f2-2). Nevertheless, all ALS-causing mutations that we examined recapitulated the phenotypes we described previously in $S O D 1^{G 93 A}$ (Fig. 2F; GFP, $40.65 \pm 16 \% ; \mathrm{GR}_{50}, 5.2 \pm 3.49 \% ; \mathrm{PR}_{50}, 0 \pm 0 \% ; \mathrm{TDP} 43^{\mathrm{A} 315 \mathrm{~T}}$, $8.75 \pm 6.39 \%)$. These results suggest that the dysregulated secretion of factors from ALS mutant muscles takes place, which in turn activates axon retraction and degeneration. Because muscles can either secrete positive or negative signaling molecules, we could not determine whether our observation within this assay originates from an increase in the release of destabilizing factors or the diminished release of positive factors. To this end, we collected muscle-CM from WT and SOD $1^{G 93 A}$ muscle cultures in complete medium containing positive factors, such as BDNF and GDNF, as was previously performed in mass culture (Nagai et al., 2007), and ultimately applied it only to the distal axons of both WT and SOD $1^{G 93 A}$ MNs (Fig. 2G,H). Interestingly, we observed that axon degeneration occurs only when SOD1 ${ }^{G 93 A}$ myocyte-CM is applied to SOD $1^{G 93 A}$ axons (Fig. $2 \mathrm{H}$; LM, $3.72 \pm$ $1.15 \%$; SOD $\left.1^{G 93 A}, 34.7 \pm 4 \%\right)$, whereas in all other combinations the axons remained intact (Fig. 2-3, available at https://doi.org/ 10.1523/JNEUROSCI.3037-17.2018.f2-3). To further determine whether Type 3 Semaphorins, such as Sema3A, contribute to MN axon degeneration in this assay, we investigated whether NRP1blocking antibody application can block this phenotype. Here again, we observed a rescue effect by this treatment (Fig. $2 \mathrm{H}$; SOD $1^{G 93 A}+$ NRP1-antibody $18.6 \pm 7 \%$ ), although the protection was incomplete. These results reinforce our hypothesis, suggesting that ALS-mutated muscles secrete destabilizing factors, such as Sema3A. Importantly, these results emphasize that $S O D 1^{G 93 A}$ MNs exhibit a higher sensitivity to degeneration, and support the MN unique vulnerability as well as the non-cellautonomous mechanism of ALS. Interestingly, previous attempts to block Sema3A signaling in $S O D 1^{G 93 A}$ mice using either a similar antibody approach or by crossing transgenic mice expressing a truncated form of Sema3A with SOD $1^{G 93 A}$ mice also resulted in only a mild improvement or none at all of motor functions (Venkova et al., 2014; Moloney et al., 2017). This suggests that Sema3A plays a complex role in MNs and that perhaps other related proteins are involved. This also led us to investigate whether a wider deregulation of secreted factors released by the diseased muscles exists. Indeed, examining other members of the Semaphorin family, we found that the percentage of NMJs expressing Sema3B, as well as NRP2 is elevated in the SOD $1^{\text {G93A }}$ ALS model (Fig. 2-4, available at https://doi.org/10.1523/JNEUROSCI.303717.2018.f2-4). Therefore, we concluded that the destabilizing effect of ALS muscles over MN axons involves more than a single factor; thus, it cannot be blocked or rescued by targeting one factor at a time. Moreover, the multiplicity of effectors suggests that a higher-order regulator, such as miRNA, might be involved in this process.

\section{miR126-5p is downregulated in ALS models and modulates} Sema3A, Sema3B, NRP1, and NRP2 protein expression levels To identify the mechanism underlying the elevated levels of various secreted destabilizing factors in muscles of ALS models, we scanned for alterations in miRNAs (mIRs) that can regulate the expression of multiple proteins. miRs have been previously linked to MN toxicity in ALS (Haramati et al., 2010). We used Nanostring miRNA-chip technology to screen for alterations in $\sim 800$ miRs of presymptomatic P60 SOD $1^{\text {G93A }}$ mice and their LM controls. The screen yielded 8 significantly altered miRs (Fig. 3A; Fig. 3-1, available at https://doi.org/10.1523/JNEUROSCI.303717.2018.f3-1). Because we found that Sema3A levels were elevated in muscles, we narrowed our focus to those miRs that were reduced and that could regulate its expression, specifically miR126-5p and miR133a (Fig. 3B; the mean fold change over LM: $S O D 1^{G 93 A}, 0.74 \pm 0.03$; LM, $1 \pm 0.03$; Fig. $3-1$, available at https://doi.org/10.1523/JNEUROSCI.3037-17.2018.f3-1). A targeted search for these miRs in databases (miRDB, Pictar, miRbase, and miRTarBase) revealed that both miRs are predicted to regulate Semaphorin signaling genes as well as other relevant transcripts of ALS-related genes. Interestingly, we previously described deep-sequencing analyses of primary MN cultures expressing SOD $1^{G 93 A}$ or TDP43 ${ }^{\mathrm{A} 315 \mathrm{~T}}$ and demonstrated that miR126-5p is also correspondingly decreased in diseased $\mathrm{MN}$ axons, but not in their soma (Rotem et al., 2017). This information led us to further focus our investigation on miR126-5p. We used qPCR to validate that miR-126-5p levels in SOD ${ }^{\text {G93A }} \mathrm{GC}$ muscles point to a similar trend (Fig. $3 C$; the mean fold change over LM: SOD $\left.1^{G 93 A}, 0.47 \pm 0.2 ; \mathrm{LM}, 1 \pm 0.45\right)$. To verify that miR126-5p can regulate the expression of Semaphorin3 and Neuropilin signaling members, we transfected HeLa cells, which are known to endogenously express Sema3A, Sema3B, NRP1, and NRP2 (Fujita et al., 2001), with miR126-5p or with the irrelevant miR142, which is not predicted to target any of these genes, 


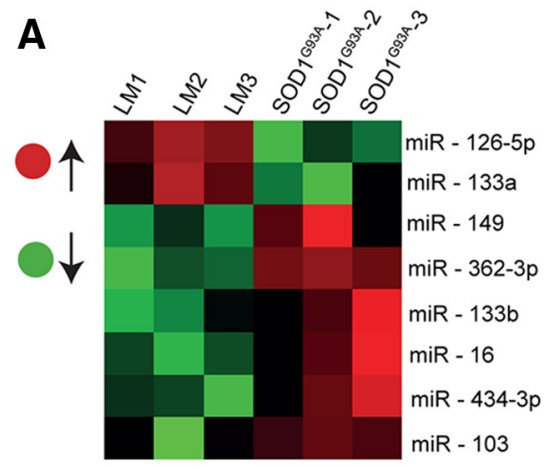

B
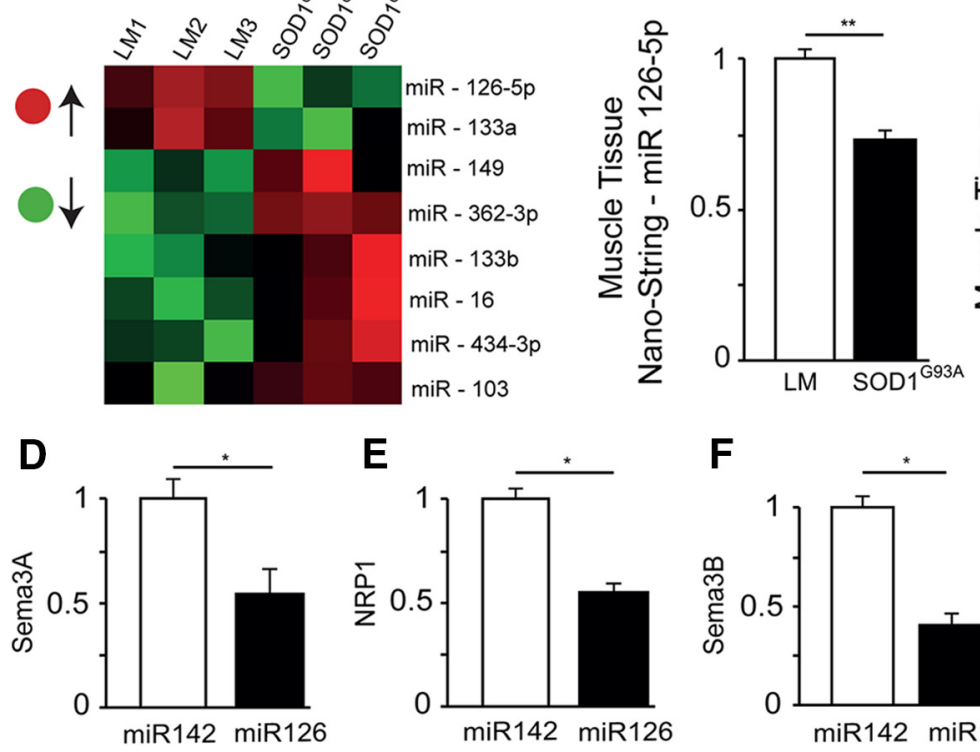

E

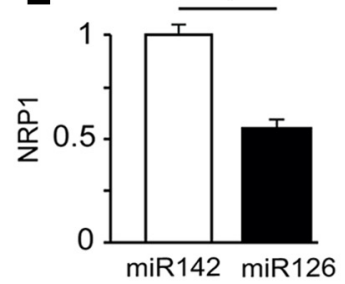

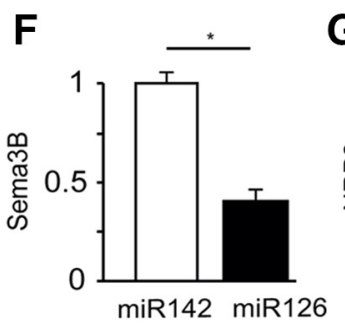

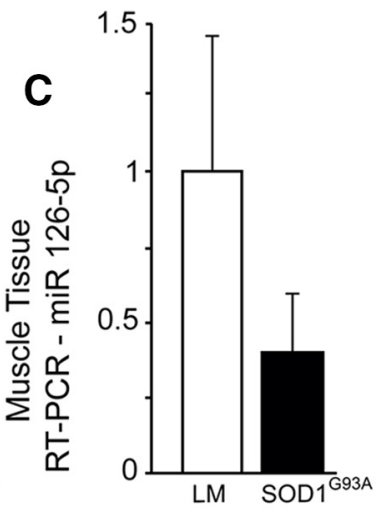

G

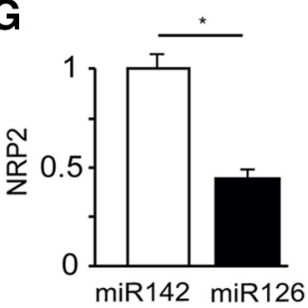

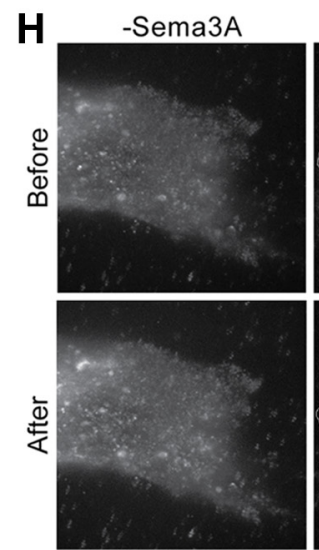

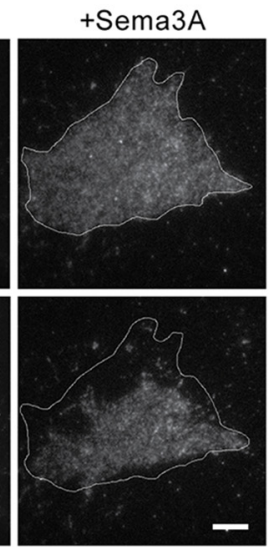

I

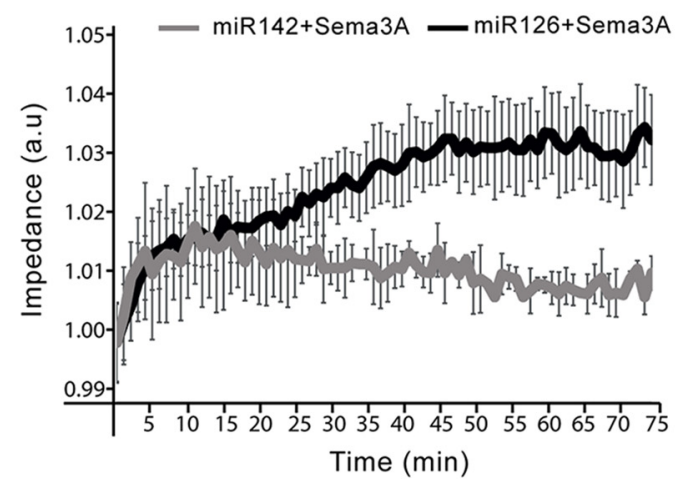

Figure 3. miR126-5p is depleted in SOD ${ }^{693 A}$ muscles and regulates Sema3 and NRP expression. $A$, NanoString chip screen heat map of significantly altered miRs in P60 muscles of SOD $1^{693 A}$ compared with LM mice (extended table under Figure 3-1, https://doi.org/10.1523/JNEUROSCI.3037-17.2018.f3-1). Red and green represent a high or low abundance of miRs, respectively. ${ }^{*} p<$ 0.05 (Student's $t$ test; $n=3$ ). $B$, miR126-5p was the most significantly downregulated miRNA in S0D $1^{693 A}$ muscles (Student's $t$ test; $n=3,{ }^{* *} p=0.003$ ). $C, q P C R$ analysis of P60 GC muscle extracts further validates the decrease in miR 126-5p in SOD ${ }^{G 93 A}(n=3) . D-G, q P C R$ analysis of Sema3A, NRP1, Sema3B, and NRP2 transcript levels in HeLa cells overexpressing either miR126-5p or miR142 demonstrates a reduction in their expression levels specifically under miR126-5p overexpression (Student's test; $n=3,{ }^{*} p=0.0438,{ }^{*} p=0.034,{ }^{*} p=0.031$, and ${ }^{*} p=0.0434$, respectively). $\boldsymbol{H}$, Representative TIRF images of U87MG cells reveal a detachment of the cell membrane from the culture dish surface after Sema3A is added to the culture medium. Scale bar, $10 \mu \mathrm{m}$. $\boldsymbol{I}$, Impedance recording of live cells over time shows that U87MG cells overexpressing miR126-5p are unresponsive to Sema3A added to the culture medium because their impedance continuously increases, whereas the impedance of U87MG cells overexpressing miR142 decreases after treatment (Figure 3-2, https://doi.org/10.1523/JNEUROSCI.3037-17.2018.f3-2).

as a negative control. To this end, we isolated RNA from these cultures and performed qPCR analysis to determine the mRNA levels of Sema3A, Sema3B, NRP1, and NRP2 (Fig. 3D-G). Our results indicate that miR126-5p specifically targets Sema3A, NRP1, Sema3B, and NRP2 (RT-PCR: mean $\triangle$ Ct-NRP1: miR126, $3.79 \pm 0.71 ;$ miR142, $2.83 \pm 0.57 ; \Delta \mathrm{Ct}-\mathrm{Sema} 3 \mathrm{~A}: \mathrm{miR} 126,4.84 \pm$ 0.22; miR142, $3.84 \pm 0.34$; $\Delta$ Ct-NRP2: miR126, $7.6 \pm 0.30$; miR142, $6.2 \pm 0.37$; $\Delta$ Ct-Sema3B: miR126, $8.1 \pm 0.10$; miR142, $7.05 \pm 0.14)$. To investigate whether miR126-5p overexpression can also inhibit Sema3A function, we used a recently described impedance-based approach. U87MG human glioblastoma cells, which express NRP1 (Fig. 3-2A, available at https://doi.org/ 10.1523/JNEUROSCI.3037-17.2018.f3-2) and were used previously specifically in this assay (Birger et al., 2015), were transfected to overexpress miR126-5p or miR142 as a control.
One day after transfection, cells were resuspended and plated in xCELLigence multiwell electric plates. The next day, Sema3A was added to the cultures, and any morphological or adhesive changes were monitored by the impedance readout. As demonstrated by TIRF imaging (Fig. $3 H$ ), adding Sema3A to responsive cells, such as U87MG cells, induces their detachment from the culture dish. This detachment can be measured as a decrease in impedance (Fig. 3-2B, available at https://doi.org/10.1523/ JNEUROSCI.3037-17.2018.f3-2). Shortly after Sema3A was added to the cultures, cells expressing miR142 exhibited decreased impedance, whereas cells expressing miR126-5p did not respond to Sema3A in the medium and kept growing with a corresponding increase in impedance (Fig. 3I). Hence, we showed that the excess production of destabilizing factors in ALS is likely to be mediated downstream of a deregulation in miR126-5p. 
A

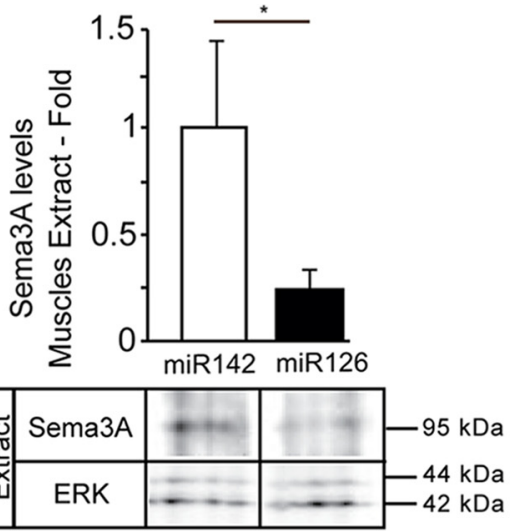

B
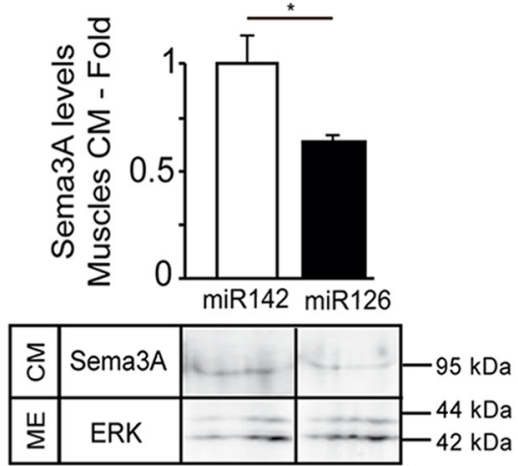

C

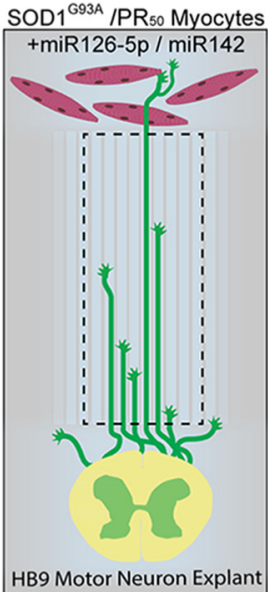

D
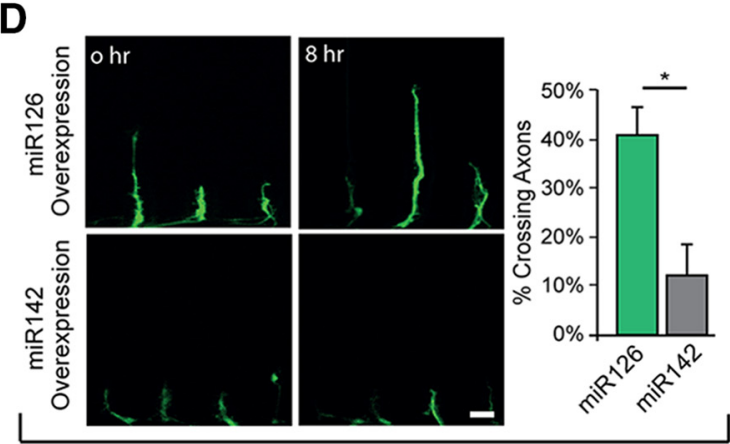

$F$

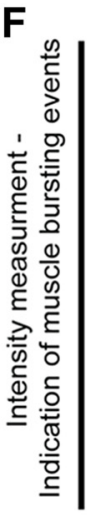

SOD1 ${ }^{\text {G93A }}$

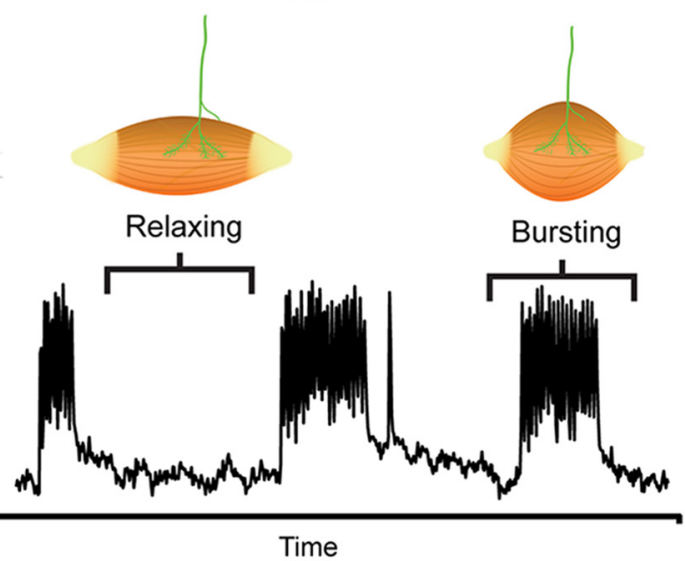

E

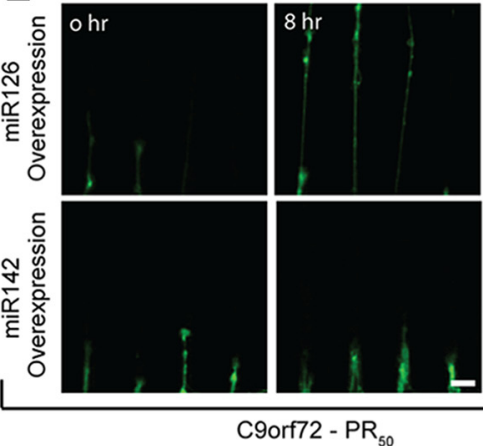

G

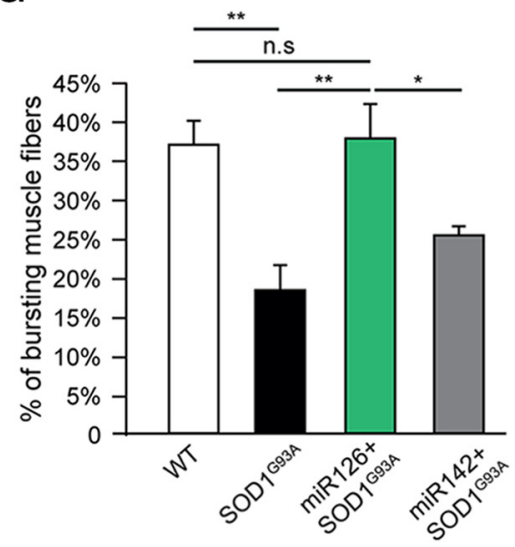

Figure 4. Overexpression of miR126-5p in primary $50 D 1^{693 A}$ myocytes blocks motor axon degeneration and preserves NMJ activity in a compartmental coculture. $\boldsymbol{A}, \boldsymbol{B}$, Western blot analysis of transfected myocyte extract overexpressing miR126-5p or miR142 and their CM validates miR126-5p as a regulator of Sema3A specifically in muscles. ERK was used as a loading control (Student's $t$ test, $n=3,{ }^{*} p=0.0499$ and ${ }^{*} p=0.05$, respectively). C, Schematic view of the experimental procedure in $\boldsymbol{D}, E$. HB9::GFP SC explants and primary myocytes of SOD $1^{693 A}$ mice were cocultured in a MFC. The growth of the HB9::GFP axons was assessed both by time-lapse imaging of the microgroove compartment and by imaging axons that traversed the distal compartment. $\boldsymbol{D}$, Representative time-lapse images and quantification of HB9::GFP axon growth when cocultured with SOD1 ${ }^{\text {miR126 }}$ myocytes (top) or SOD1 ${ }^{\text {miR } 142}$ myocytes (bottom). SOD1 ${ }^{\text {miR } 126}$ myocytes in the distal compartment enhanced the axonal traversal of the distal compartment compared with the SOD1 ${ }^{\text {miR142 }}$ myocytes. The data are shown as the mean rate of axons that traversed the distal compartment out of the total number of axons in each field \pm SEM (Student's $t$ test, $n=3,{ }^{*} p=0.04216$ ). E, Representative time-lapse images and quantification of HB9::GFP axon growth when cocultured with PR $R_{50}^{\text {miR126 }}$ myocytes (top) or PR ${ }_{50}^{\text {miR142 }}$ myocytes (bottom). $\mathrm{PR}_{50}^{\text {miR126 }}$ myocytes in the distal compartment enhanced the axonal traversal of the distal compartment compared with PR ${ }_{50}^{\text {miR142 }}$ myocytes. The data are shown as the mean rate of axons that traversed the distal compartment out of the total number of axons in each field \pm SEM (Student's t test, $n=3$, *** $p=0.0039$ ). $F$, Representative myocyte contraction plot showing the bursting contractile behavior of innervated myocytes in vitro. G, Quantification of the percentage of innervated myocytes that contract in a bursting pattern shows a diminished rate of bursting behavior in SOD $1^{693 A}$ myocytes compared with $\mathrm{LM}$ controls. SOD1 ${ }^{\text {miR126 }}$ myocytes show an increase in the rate of bursting myocytes back to the $L M$ levels. The data are shown as the mean percentage of bursting myocytes \pm SEM (Student's $t$ test, $\left.n=3,{ }^{*} p=0.0291,{ }^{*} p=0.0156,{ }^{* *} p=0.005656\right) .{ }^{* * *} p<0.001$.

\section{Overexpression of miR126-5p can block SOD $1^{G 93 A}$ muscle toxicity}

We overexpressed miR126-5p in SOD ${ }^{\mathrm{G} 93 \mathrm{~A}}$ myocyte cultures and quantified Sema3A levels in their culture extract as well as in their CM. Western blot analysis indicated that Sema3A levels in both the culture extract and CM are depleted, compared with miR142
(Fig. $4 A, B$; the mean fold change over SOD1 ${ }^{\text {miR142}}$ : Muscle extract-SOD $1^{\text {miR } 126}, 0.24 \pm 0.1 ;$ SOD $1^{\text {miR142 }}, 1 \pm 0.4$ MuscleCM-SOD1 ${ }^{\text {miR } 126}, 0.63 \pm 0.03 ;$ SOD $\left.1^{\text {miR } 142}, 1 \pm 0.13\right)$. Next, we investigated whether overexpressing miR126-5p in both $S O D 1^{G 93 A}$ and $\mathrm{PR}_{50}$ myocytes can rescue the negative effect on $\mathrm{MN}$ growth that we observed before. To this end, primary myo- 


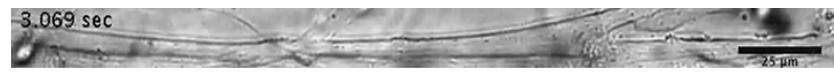

Movie 5. Myocyte exhibiting bursting contracted behavior. Timelapse image series of innervated SOD ${ }^{\mathrm{G} 93 \mathrm{~A}}$ expressing miR126-5p myocyte exhibiting bursting contracted behavior. Scale bar, $25 \mu \mathrm{m}$.
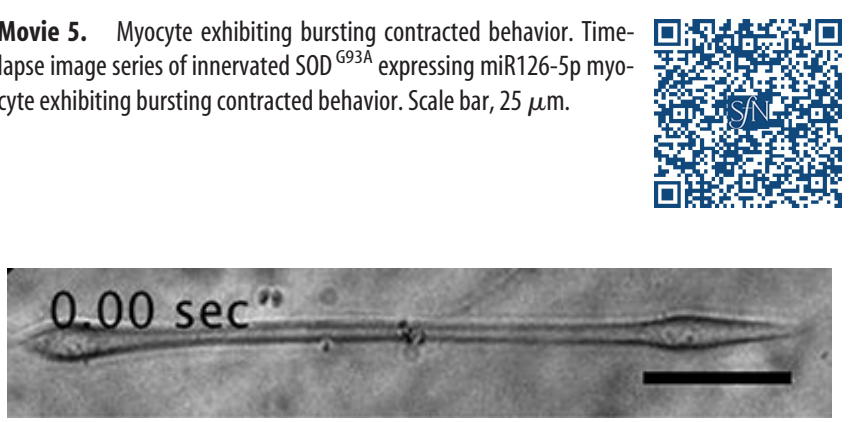

Movie 6. Myocyte exhibiting nonbursting contracted behavior. Time-lapse image series of innervated SOD ${ }^{\text {G93A }}$ expressing miR142 myocyte exhibiting nonbursting behavior. Scale bar, $25 \mu \mathrm{m}$.

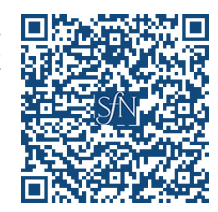

blasts were transfected to overexpress either miR126-5p $\left(\mathrm{SOD} 1^{\text {miR126}_{2}} ; \mathrm{PR}_{50}{ }^{\text {miR126 }}\right.$ ) or miR142 (SOD1 ${ }^{\text {miR142 }} ; \mathrm{PR}_{50}{ }^{\text {miR142 }}$ ) and were then plated in the distal compartment of the MFC. Myoblasts were differentiated into mature myocytes while expressing the miRs for $7 \mathrm{~d}$, after which HB9::GFP explants were cultured in the proximal compartment. Once axons reached the microgrooves, their extension toward the muscle compartment was monitored for $16 \mathrm{~h}$ (Fig. 4C). Evidently, cocultures with SOD1 ${ }^{\text {miR126 }}$ and $\mathrm{PR}_{50}{ }^{\text {miR126 }}$ myocytes retained wild-type behavior and manifested a clear rescue effect on the rate of axon traversal (Fig. 4D,E; the mean traversal rate of axons: SOD1 ${ }^{\text {miR126, }}$ $40.77 \pm 6.68 \%$; SOD ${ }^{\text {miR } 142}, 12 \pm 7.6 \%$ PR $_{50}{ }^{\text {miR } 126}, 45.6 \pm$ $9.4 \%$; PR50 $\left.{ }^{\mathrm{miR} 142}, 16 \pm 3.6 \%\right)$. Thus far, we have shown that myocytes expressing various ALS-linked mutations facilitate MN axon degeneration and delay their growth in a simplified compartmental coculture assay. However, while observing the cocultures for longer periods, we found that axons eventually do traverse the muscle compartment and form functional synapses with the myocytes. Using an image-based method that we recently developed to quantify contraction and assess the innervation in in vitro cocultures (Ionescu et al., 2016; Zahavi et al., 2017), we observed that the contractile behavior of innervated $S O D 1^{G 93 A}$ myocytes is significantly different from that of innervated LM myocytes, which tend to contract in a bursting pattern (Fig. 4F, G; Movies 5, 6). Whereas 37\% of innervated myocytes contract in a bursting pattern, only $18 \%$ of the innervated $S O D 1^{G 93 A}$ myocytes contract in this pattern (the mean rate of bursting innervated myocytes: LM, $37.23 \pm 2.8 \%$; SOD $1^{\text {G93A }}$, $18.5 \pm 2.03 \%)$. Strikingly, SOD ${ }^{\text {miR } 126}$ myocytes retain the same rate of bursting myocytes as the LM myocytes (Fig. $4 G$; the mean rate of bursting innervated myocytes: SOD $1^{\text {miR126 }}, 37.66 \pm$ 4.29\%; SOD $\left.1^{\mathrm{miR} 142}, 26.26 \pm 0.59 \%\right)$. Hence, miR126-5p is an effective regulator of muscle-secreted factors, such as Sema3, and can rescue the detrimental effect of destabilizing factors on MN axons, as well as on NMJ function and maintenance in vitro.

\section{miR126-5p transiently rescues early motor phenotypes of} SOD1 $1^{\text {G93A }}$ mice in vivo

NMJ disruption, muscle morphology abnormalities, and hindlimb misprints are major phenotypes in SOD $1^{G 93 A}$ mice (Gurney et al., 1994). To determine whether miR126-5p can moderate those phenotypes, we injected $S O D 1^{G 93 A}$ mice with either pLL-eGFP-
miR126 (SOD1 ${ }^{\text {miR126}}$ ) or pLL-eGFP-miR142 (SOD1 ${ }^{\text {miR142 }}$ ) into the right and left GC muscles of presymptomatic mice (P60), respectively (Fig. 5A). Virus expression was validated both in vitro on MNs and in muscle cultures (Fig. 5-1A, available at https://doi.org/10.1523/JNEUROSCI.3037-17.2018.f5-1) as well as in vivo at the transcript and protein levels (Fig. 5-1 B, $C$, available at https://doi.org/10.1523/JNEUROSCI.3037-17.2018.f5-1). Importantly, we observed a decrease in the number of NMJs expressing Sema3A in the pLL-eGFP-miR126-5p-injected GC muscles in comparison with the miR142 group, suggesting that miR-126-5p is active in the injected tissue (Fig. 5-1D, available at https://doi.org/10.1523/JNEUROSCI.3037-17.2018.f5-1). Next, we performed a series of histological analyses, followed by motor behavioral tests at two time points after injection: at the age at which mice typically begin exhibiting ALS phenotypes (P90) as well as in the disease end stage (P120) (Fischer et al., 2004). Because NMJ disruption is a key process in ALS, we sought to determine whether overexpression of miR126-5p results in reduced NMJ disruption. Briefly, both the left and right GC muscles were fixed and stained for synaptic markers of the NMJ (Fig. 5B). Quantifying the percentage of intact NMJs at P90 injected mice revealed a significantly higher innervation rate in miR126-5pexpressing muscles compared with both mock-treated and SOD $1^{\text {G93A }}$ muscles (Fig. $5 C$; P90: WT, $71.58 \pm 3.32 \%$; SOD ${ }^{\mathrm{G} 93 \mathrm{~A}}$, $42.58 \pm 2.64 \%$; SOD ${ }^{\text {miR } 126}, 64.25 \pm 5.8 \%$; SOD $1^{\text {miR } 142}$, $46.54 \pm 7.2 \%)$. Furthermore, careful analysis at P120 also identified a mild rescue by miR-126-5p overexpression. (Fig. $5 C$; P120: WT, $74.35 \pm 4.74 \%$; SOD ${ }^{\text {G93A }}, 20.12 \pm 5.01 \%$; SOD $1^{\text {miR } 126}, 30.82 \pm 3.97 \%$; SOD $\left.1^{\text {miR } 142}, 18.18 \pm 3.12 \%\right)$. Next, we performed histological analyses to determine muscle fiber wasting and tissue abnormalities (Fig. 5D,E). P120 GC muscles of WT, SOD $1^{G 93 A}$, and both SOD $1^{\text {miR126 }}$ and SOD $1^{\text {miR142 }}$ were stained with $\mathrm{H} \& \mathrm{E}$ for histological examination, and the minimal diameter of myofibers was analyzed as described in Materials and Methods. We observed a mild, but significant, increase in the minimal fiber size of the SOD $1^{\text {miR126}}$-injected muscle compared with the SOD $1^{\text {miR } 142}$ mock control (Fig. 5C; P120: WT, $40.25 \pm$ $2.28 \%$; SOD $^{\text {G93A }}, 18.5 \pm 0.64 \%$; SOD $1^{\text {miR126 }}, 23 \pm 1.87$; SOD $1^{\text {miR142 }}, 19 \pm 1.47$ ). Last, we performed a behavioral test using the CatWalk gait analysis technique. This video-based method is a computerized version of the ink bath assay and provides an objective and dynamic wide range of gait analyses (Deumens et al., 2007). Moreover, it has been used before specifically with the SOD $1^{G 93 A}$ mouse model and displayed significant differences in several parameters (Mead et al., 2011; Gerber et al., 2012) (Fig. 5F). One output is the Mean Stand Index (MSI), which measures the speed at which the paws detach from the walking surface. Because aged SOD $1^{G 93 A}$ mice suffer motor defects, their MSI values for both hindlimbs are dramatically lower than their LM values. Remarkably, the MSI values of the SOD1 ${ }^{\text {miR126 }}$ injected limbs were significantly higher at P90 and similar to the LM control values, whereas the SOD1 ${ }^{\mathrm{miR} 142}$-injected limb was reminiscent of typical SOD $1^{G 93 A}$ behavior (Fig. $5 G$; mean fold change over WT: SOD1 $1^{G 93 A}, 0.68 \pm 0.02$; SOD $1^{\text {miR126 }}, 0.74 \pm$ 0.06; SOD $\left.1^{\text {miR } 142}, 0.65 \pm 0.04 ; \mathrm{LM}, 1 \pm 0.04\right)$. We also examined other established parameters that have been shown to be altered in the SOD ${ }^{\mathrm{G} 93 \mathrm{~A}}$ model (Mead et al., 2011). We specifically focused on the percentage of single-support parameter, which indicates the relative duration of contact of all combined paws with the glass floor, and on the base of support parameter, which indicates the average width of limb spreading between both front, or both hindpaws. Remarkably, we observed a significant rescue phenotype for both parameters in the injected mice at age of $\mathrm{P} 90$. 
A

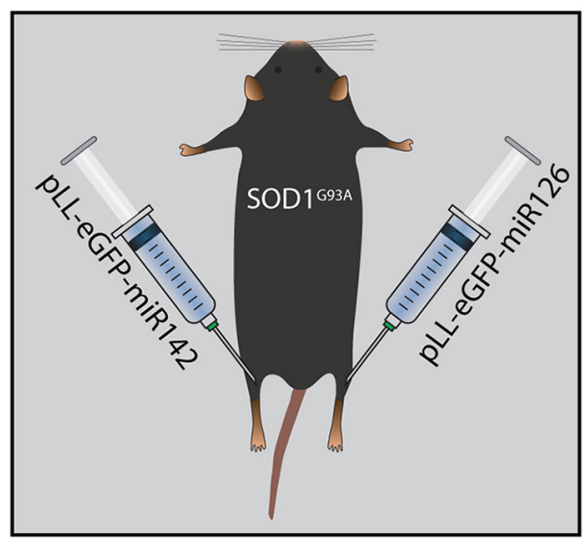

C

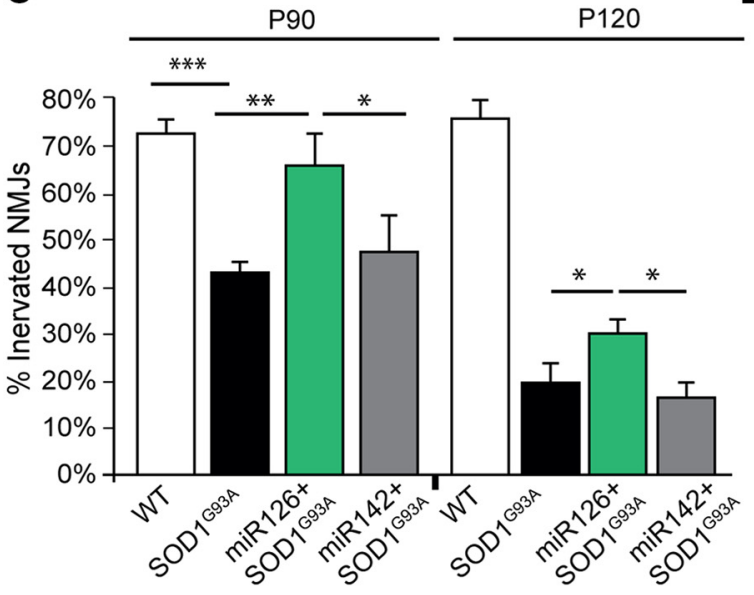

B

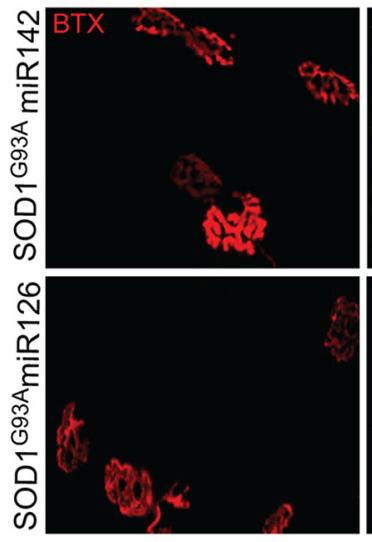

D

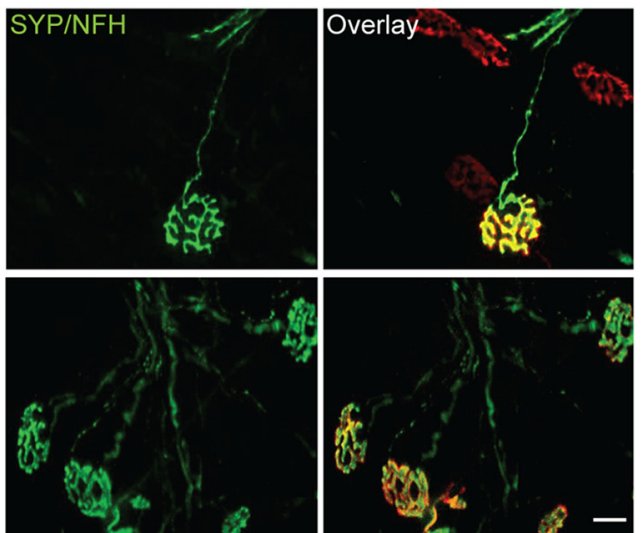

E
WT

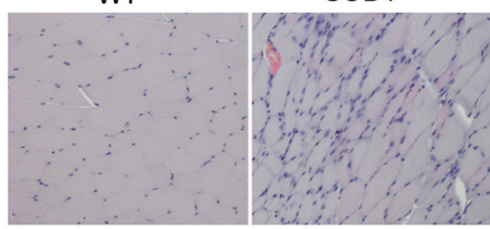

SOD ${ }^{G 93 A}$ miR126-5p SOD ${ }^{G 93 A} \operatorname{miR} 142$
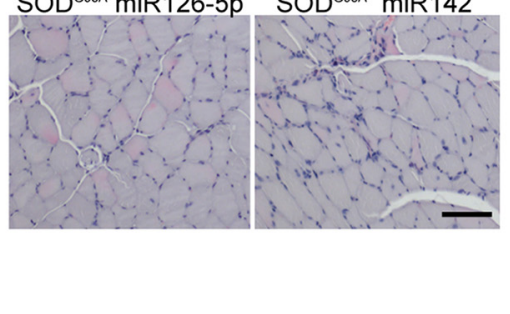

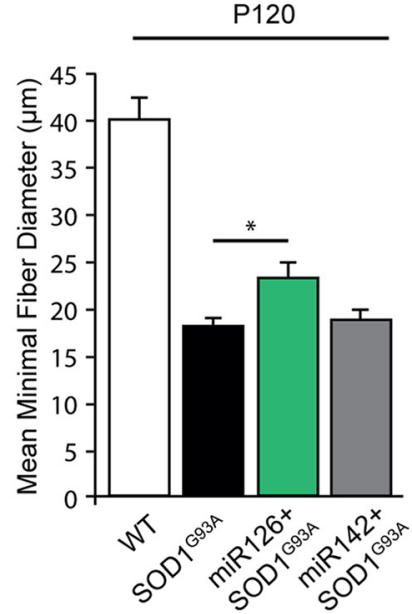

F

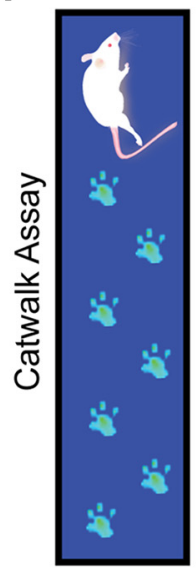

G

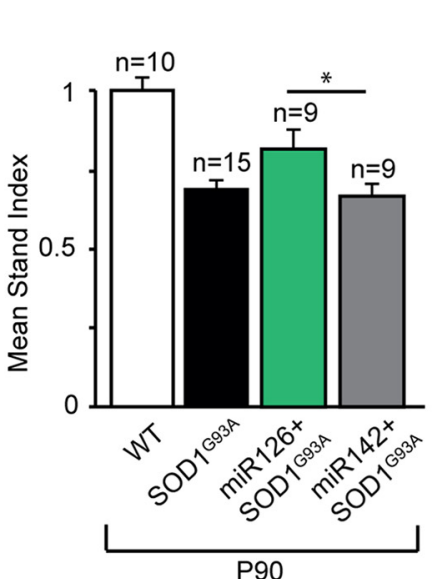

$\mathbf{H}$

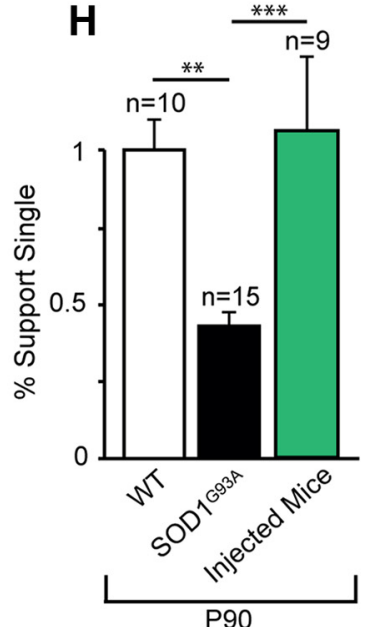

I

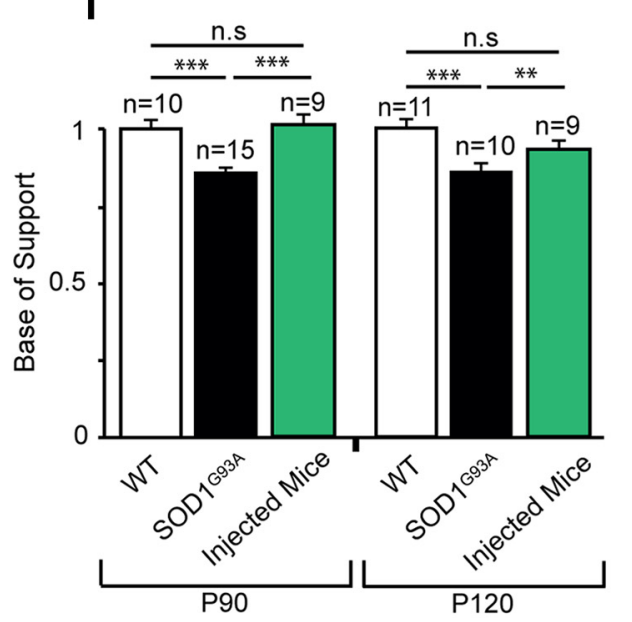

Figure 5. pLL-eGFP-miR126-5p injected into GC muscles of presymptomatic SOD1693A mice transiently rescues the early phenotype appearance in vivo. $\boldsymbol{A}$, Schematic view of the in vivo experimental procedure. SOD1 $1^{693 A}$ mice were injected with either pLL-eGFP-miR126-5p or pLL-eGFP-miR142 in their right or left GC muscles, respectively. Viral infection was validated (Figure 5-1, available at https://doi.org/10.1523/JNEUROSCI.3037-17.2018.f5-1). B, Representative whole-mount NMJ immunostaining of $\sim$ P90 SOD1 ${ }^{693 A}$ GC muscles injected with either miR126-5p or miR142 lenti vectors. Red represents BTX. Green represents NFH + synaptophysin in presynaptic neurons. Scale bar, $20 \mu \mathrm{m}$. C, The percentage of innervated NMJs in miR126-5p-injected muscles is higher compared with its controls in both P90 and P120 (P90: Student's $t$ test, $n=6,{ }^{*} p=0.0475,{ }^{* *} p=0.001245 ;$ P120: Student's t test, $n=5,{ }^{*} p=0.043,{ }^{* *} p=0.0096$ ). D, Representative histological images of P120 WT, SOD1 ${ }^{693 A}$, miR126-5p, and miR142 GC muscle cross sections after H\&E staining. Scale bar, $100 \mu \mathrm{m}$. $E$, Semiquantification of a GC cross section from D shows a significant increase in the minimal muscle fiber diameter of muscles that were injected with miR126-5p (P120: Student's test, $n=4,{ }^{*} p=0.031$ ). $\boldsymbol{F}$, Illustration of the CatWalk XT gait analysis system that monitors mouse footprints. G, Gait analysis MSI parameter indicates the speed at which the paw loses contact with the surface. The MSI for the P90 miR126-5p-injected limbs was significantly higher than for miR142-injected limbs (Student's $t$ test, ${ }^{*} p=0.0355$ ). $\boldsymbol{H}$, Gait analysis percentage single-support parameter indicates the relative duration of contact of a single paw on the glass floor. The percentage in which the injected animals were used along the run with a single paw was significantly higher compared with SOD $1^{693 A}$ mice and showed similarity to the WT control (Student's $t$ test, SOD1 ${ }^{G 93 A}$-injected, ${ }^{* * *} p=0.0004$; WT-SOD1 ${ }^{693 A},{ }^{* * *} p=0.000003$ ). $I$, Gait analysis base of support parameter indicates the average width between the hindpaws. The base of support of both P90- and P120-injected mice was significant higher compared with SOD $1^{\text {G93A }}$ (Student's t test, P90 SOD $1^{\text {G93A }}$-injected, ${ }^{* * *} p=0.0000006$; WT-SOD $1^{693 A}$, ${ }^{* * *} p=0.000007$; P120 SOD $1^{693 A}$-injected, ${ }^{* * *} p=0.0 .00003 ;$ WT-SOD1 $1^{693 A},{ }^{* * *} p=0.000000009$ ). 


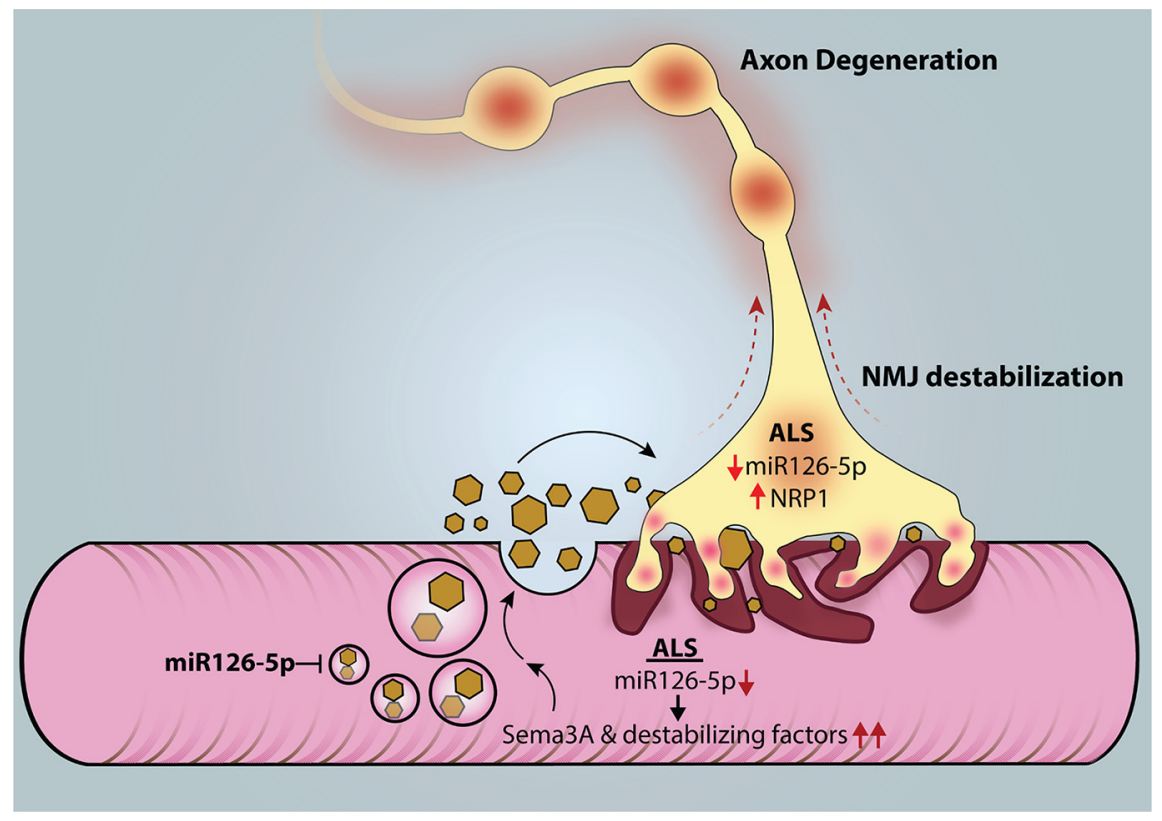

Figure 6. Alterations in Semaphorin3A regulation by miR126-5p trigger MN degeneration in ALS. miR126-5p is a negative regulator of Sema3 signaling in skeletal muscles. Downregulation of miR126-5p in ALS disease drives the overexpression and secretion of Sema3A and potentially other NMJ-destabilizing factors in skeletal muscles. The downregulation in miR126-5p in diseased MNs drives the overexpression of NRP1 specifically in axons. The excess binding and activation of the NRP1 receptor by its overexpressed ligand Sema3A as a result of miR126-5p alteration promote NMJ disruption and axon degeneration in a spatially confined process.

Furthermore, the improvement in base of support parameter persisted also in P120 (Fig. 5 H, I; Percentage of Support Single: $S O D 1^{G 93 A}, 0.43 \pm 0.05$; injected, $1.06 \pm 0.24 ; \mathrm{LM}, 1 \pm 0.1$; Base of Support, P90: $S O D 1^{G 93 A}, 0.87 \pm 0.01$; injected, $1.02 \pm 0.02 ; \mathrm{LM}$, $1 \pm 0.02$; P120: SOD1 ${ }^{G 93 A}, 0.858 \pm 0.02$; injected, $0.95 \pm 0.02$; $\mathrm{LM}, 1 \pm 0.02)$.

Together, we demonstrated in vivo that miR $126-5 \mathrm{p}$ reduces the detrimental effects of muscle-secreted destabilizing factors, such as Sema3A, on MN axons and motor function in ALS models.

\section{Discussion}

In this work, we demonstrated that the muscle toxicity in ALS is mediated by miR126-5p. We provided one specific mechanism for a well-described molecule (Sema3A), by which miR126-5p contributes to ALS pathology. We have also demonstrated that miR126-5p alterations facilitate axon degeneration and NMJ disruption in an ALS model as an outcome of presymptomatic elevations in the production and secretion of their target genes, which encode for destabilizing factors, such as Sema3 family members. Overexpressing miR126-5p in SOD $1^{G 93 A}$ muscles inhibits the neurodegenerative process. These findings reveal how alterations in miR126-5p can be toxic to MNs, and identify a noncell-autonomous neurodegeneration process in ALS (Fig. 6).

\section{miR126-5p as a master regulator of proper NMJ function}

Our results indicate that the expression of ALS-causative mutations results in the secretion of repellent factors, including a number of Type 3 Semaphorins and potentially other factors. It is thus likely that a general gene repression mechanism, specifically miR system, is altered under such conditions. This assumption is also consistent with the fact that miR alterations are apparent in various neurodegenerative diseases, including ALS (Haramati et al., 2010). Here we identified such an miR and showed how alter- ations in this specific miR can regulate the essential signaling pathways in MNs and can trigger neurodegeneration. Intriguingly, and in line with our findings, a very recent paper demonstrated a mechanism by which miR126-5p modulates Sema3A expression through SetD5 expression, and it emphasizes its positive effect on retinal endothelial cells' survival (Villain et al., 2018). However, aside from targeting Sema3A and Sema3B, as well as NRP1 and NRP2, miR126-5p is predicted to regulate other Semaphorin signaling factors, such as Sema6D, PLXNA2, JNK2, JNK3, and PTEN. In addition, miR126-5p can regulate the ALS and motor-unit-related genes VEGF-A, SPAST, MMPs (Kaplan et al., 2014), AGRIN (Vilmont et al., 2016), and C9orf72, which are directly involved in ALS. Therefore, miR126-5p can serve as a master regulator of NMJ health by controlling multiple signaling pathways.

\section{Sema3 alterations in ALS: settling the contradictory reports}

A critical initiating event for the mechanism outlined above is the alterations in Sema3 signaling in ALS models and patients. Sema3 family members were previously found to be upregulated in terminal Schwann cells in the NMJs of SOD $1^{\text {G93A }}$ mice (De Winter et al., 2006). Recently, Sema3A was also shown to be elevated in the motor cortex of postmortem ALS patients but not in their SC (Körner et al., 2016). Consistent with this, NRP1 antibodies, blocking the obligatory binding receptor for Sema3A, were injected into $S O D 1^{G 93 A}$ mice as a potential treatment (Venkova et al., 2014). However, anti-NRP1 blocking antibody had only a modest effect. Moreover, a recent study demonstrated that crossing mice expressing a truncated form of Sema3A with SOD $1^{G 93 A}$ mice did not result in any rescue effect (Moloney et al., 2017). An explanation for a minor effect or not at all, as a result of blocking Sema3A activity, could be based on the idea of multiple toxic factors that play a role in ALS pathology. Another explanation for this contradiction could be the fact that Sema3A plays a more complex role in the biology of MNs. Indeed, Sema3A was shown to increase survival when added to mass cultures of mouse MNs (Molofsky et al., 2014) and human MNs (Birger et al., 2018). Consistent with this, deletion of the Sema3A gene specifically in spinal astrocytes resulted in a gradual loss of spinal MNs (Molofsky et al., 2014), thus suggesting that Sema3A has a positive effect when introduced near the cell body. When these findings are together with our results, apparently Sema3A has both positive and negative effects on MNs, perhaps depending on its specific subcellular localization. When Sema3A is secreted from muscles and targets distal axons at NMJs, it mediates their destabilization; however, when it is secreted by spinal astrocytes and targets MN soma, it acts as a survival factor. Thus, it is perhaps not surprising that a genetic approach to inhibit Sema3A in all cells in a mouse model of ALS had no effect in inhibiting the symptoms. The injection of anti-NRP1 may have been a bit more beneficial possibly either because it was able to inhibit Sema3A outside the CNS more effectively, or alternatively, because NRP1 blocks other Type 3 Semaphorins as well. 


\section{Autonomous versus non-cell-autonomous contributions to ALS progression}

ALS is considered a complex disease, with unique MN features as well as non-cell-autonomous contributions (Ilieva et al., 2009; Musarò, 2013). Some evidence suggests that the NMJ is the first compartment to be disrupted in ALS rather than the MN soma; the disease is recognized as distal axonopathy in a non-cellautonomous process (Fischer et al., 2004; Moloney et al., 2014). Two main cell populations that have been shown to play a role in distal axonopathy are glia and muscle cells, which secrete factors that influence MN survival and health (Moloney et al., 2014; Tsitkanou et al., 2016). However, the complexity of the disease and the involvement of several tissues raise controversies regarding the contribution of each tissue to the disease pathology. With skeletal muscle, few works have concluded that muscles do not play a role in ALS pathology. Reducing hSOD ${ }^{\mathrm{G} 93 \mathrm{~A}}$ levels by injecting siRNA against its transcript directly into muscles of the SOD ${ }^{\text {G93A }}$ mouse model, as well as crossing Lox SOD ${ }^{\text {G37R }}$ with the Cre coding sequence under the control of the muscle creatine kinase promoter, or performing manipulations using Follistatin did not affect the disease onset and survival (Miller et al., 2006). In vitro application of muscle-CM from $\mathrm{SOD}^{\mathrm{G} 93 \mathrm{~A}}$-expressing muscle on healthy mass culture and ES cell-derived MNs resulted in no effect (Nagai et al., 2007). However, in contrast with these findings, evidence indicates that overexpressing mutant SOD1 protein specifically in healthy skeletal muscle induces an ALS phenotype and the degeneration of MNs, supporting a direct role for muscle in ALS physiology (Dobrowolny et al., 2008; Wong and Martin, 2010). Moreover, muscle from ALS patients and models has been shown to exhibit impaired mitochondrial function (Shi et al., 2010) and abnormalities in muscle biology (Manzano et al., 2012). Here, we demonstrated that applying presymptomatic SOD1 $1^{G 93 A}$ muscle-CM directly, and only on $S O D 1^{G 93 A}$-expressing $\mathrm{MN}$ axon tips, results in their degeneration, suggesting that both tissue types are necessary for exhibiting the disease phenotype. Furthermore, contradictory reports were published on transgenic mice expressing $S O D 1^{G 93 A}$ only in the MNs. For example, Lino et al. (2002) showed a very mild phenotype, whereas Jaarsma et al. (2008) demonstrated a significant toxic effect. In this study, we showed that muscle-secreted factors are capable of modulating MN axons. Whereas wild-type musclesecreted factors facilitate axon growth, several ALS-related mutations, expressed in muscles, result in the secretion of factors that cause retraction and degeneration when exclusively introduced to axons. At least one of these factors is Sema3A. The secretion of Sema3A by the muscle itself is likely to contribute to the instability of the MN axons. However, our results also show that ALS mutant muscles themselves cause axon degeneration and a delay in axon growth toward the muscles, but eventually the connections between axons and muscles are established. Thus, at least in our system, apparently the non-cell-autonomous contributions of the muscle are insufficient to recapitulate all the toxic effects on MNs. However, once the MNs also carry an ALS mutation, axons are more susceptible to degeneration by mutated muscle-CM (Fig. $3 G, H$ ), thus demonstrating the critical contribution of the MNs to ALS progression.

\section{Do diseased muscles initiate axon degeneration or inhibit regeneration?}

Our data suggest that muscles are involved in modulating MN health in ALS disease. We showed, both in vivo and in vitro, that muscles secrete destabilizing factors, such as Sema3A, as well as facilitate axon degeneration and NMJ disruption. Intriguingly, a previous study demonstrated that Sema3A expression is limited only to myosin IIb positive fibers, which are prone to be disrupted first in ALS (De Winter et al., 2006). These data support our findings in which the percentage of NMJs that express Sema3A and NRP1 is reduced at the end stage of the disease, most likely along with the fast fatigue NMJs. However, although the suggested mechanism involves muscle-MN interaction, because of the nature of our experimental model, we cannot fully determine whether the mutated muscles act by initiating the degeneration of MN axons or by inhibiting their regrowth and NMJ repair, which was also suggested previously (Arbour et al., 2015). Perhaps muscle toxicity plays an active role in both pathways. However, future efforts should be made to resolve this issue.

\section{miRs as a potential therapeutic strategy for ALS disease}

In this paper, we demonstrated a positive effect of miR126-5p on ALS disease progression and suggested a potential therapeutic strategy for ALS disease. Nevertheless, our in vivo data show that the most significant positive effect of miR126-5p on ALS pathology was achieved at P90, whereas at later stages only modest effects were achieved. These results point to miR126-5p as a targeted treatment for an early phenotype but without a sustained beneficial contribution at later stages of ALS disease. However, keeping in mind that we injected miR126-5p into small parts of the whole GC muscle and only once at P60, as well as the fact that the efficiency of the procedure of the injection can also affect the efficacy of this treatment, we cannot rule out the possibility that a broader test of long-term efficacy will result in a stronger and more positive outcome. An alternative future study should address this issue by crossing a conditional tissue-specific knockout of miR126-5p mice with SOD $1^{\text {G93A }}$.

Considering that ALS is a multifactorial disease, and that miRs are predicted to regulate a wide range of metabolic and signaling pathways, manipulating their subcellular levels in neurons, muscles, or glia, miRs should generally be explored as a potential therapeutic strategy or tool for treatment of ALS and possibly other neurodegenerative diseases.

\section{References}

Arbour D, Tremblay E, Martineau É, Julien JP, Robitaille R (2015) Early and persistent abnormal decoding by glial cells at the neuromuscular junction in an ALS model. J Neurosci 35:688-706. CrossRef Medline

Ben-Zvi A, Yagil Z, Hagalili Y, Klein H, Lerman O, Behar O (2006) Semaphorin $3 \mathrm{~A}$ and neurotrophins: a balance between apoptosis and survival signaling in embryonic DRG neurons. J Neurochem 96:585-597. CrossRef Medline

Ben-Zvi A, Manor O, Schachner M, Yaron A, Tessier-Lavigne M, Behar O (2008) The semaphorin receptor PlexinA3 mediates neuronal apoptosis during dorsal root ganglia development. J Neurosci 28:12427-12432. CrossRef Medline

Birger A, Besser E, Reubinoff B, Behar O (2015) A new impedance based approach to test the activity of recombinant protein-semaphorins as a test case. Eur J Cell Biol 94:453-457. CrossRef Medline

Birger A, Ottolenghi M, Perez L, Reubinoff B, Behar O (2018) ALS-related human cortical and motor neurons survival is differentially affected by Sema3A. Cell Death Dis 9:256. CrossRef Medline

Buratti E (2015) Functional significance of TDP-43 mutations in disease. Adv Genet 91:1-53. CrossRef Medline

Deumens R, Jaken RJ, Marcus MA, Joosten EA (2007) The CatWalk gait analysis in assessment of both dynamic and static gait changes after adult rat sciatic nerve resection. J Neurosci Methods 164:120-130. CrossRef Medline

De Winter F, Vo T, Stam FJ, Wisman LA, Bär PR, Niclou SP, van Muiswinkel FL, Verhaagen J (2006) The expression of the chemorepellent semaphorin $3 \mathrm{~A}$ is selectively induced in terminal Schwann cells of a subset of neuromuscular synapses that display limited anatomical plasticity and 
enhanced vulnerability in motor neuron disease. Mol Cell Neurosci 32: 102-117. CrossRef Medline

Di Pietro L, Baranzini M, Berardinelli MG, Lattanzi W, Monforte M, Tasca G, Conte A, Logroscino G, Michetti F, Ricci E, Sabatelli M, Bernardini C (2017) Potential therapeutic targets for ALS: MIR206, MIR208b and MIR499 are modulated during disease progression in the skeletal muscle of patients. Sci Rep 7:9538. CrossRef Medline

Dobrowolny G, Aucello M, Rizzuto E, Beccafico S, Mammucari C, Boncompagni S, Belia S, Wannenes F, Nicoletti C, Del Prete Z, Rosenthal N, Molinaro M, Protasi F, Fanò G, Sandri M, Musarò A (2008) Skeletal muscle is a primary target of SOD1G93A-mediated toxicity. Cell Metab 8:425-436. CrossRef Medline

Dupuis L, Gonzalez de Aguilar JL, Echaniz-Laguna A, Loeffler JP (2006) Mitochondrial dysfunction in amyotrophic lateral sclerosis also affects skeletal muscle. Muscle Nerve 34:253-254. CrossRef Medline

Emde A, Hornstein E (2014) miRNAs at the interface of cellular stress and disease. EMBO J 33:1428-1437. CrossRef Medline

Fischer LR, Culver DG, Tennant P, Davis AA, Wang M, Castellano-Sanchez A, Khan J, Polak MA, Glass JD (2004) Amyotrophic lateral sclerosis is a distal axonopathy: evidence in mice and man. Exp Neurol 185:232-240. CrossRef Medline

Frey D, Schneider C, Xu L, Borg J, Spooren W, Caroni P (2000) Early and selective loss of neuromuscular synapse subtypes with low sprouting competence in motoneuron diseases. J Neurosci 20:2534-2542. CrossRef Medline

Fujita H, Zhang B, Sato K, Tanaka J, Sakanaka M (2001) Expressions of neuropilin-1, neuropilin-2 and semaphorin 3A mRNA in the rat brain after middle cerebral artery occlusion. Brain Res 914:1-14. CrossRef Medline

Gerber YN, Sabourin JC, Rabano M, Vivanco Md, Perrin FE (2012) Early functional deficit and microglial disturbances in a mouse model of amyotrophic lateral sclerosis. PLoS One 7:e36000. CrossRef Medline

Gurney ME, Pu H, Chiu AY, Dal Canto MC, Polchow CY, Alexander DD, Caliendo J, Hentati A, Kwon YW, Deng HX (1994) Motor neuron degeneration in mice that express a human $\mathrm{Cu}, \mathrm{Zn}$ superoxide dismutase mutation. Science 264:1772-1775. CrossRef Medline

Haramati S, Chapnik E, Sztainberg Y, Eilam R, Zwang R, Gershoni N, McGlinn E, Heiser PW, Wills AM, Wirguin I, Rubin LL, Misawa H, Tabin CJ, Brown R Jr, Chen A, Hornstein E (2010) miRNA malfunction causes spinal motor neuron disease. Proc Natl Acad Sci U S A 107:13111-13116. CrossRef Medline

Hawley ZC, Campos-Melo D, Droppelmann CA, Strong MJ (2017) MotomiRs: miRNAs in motor neuron function and disease. Front Mol Neurosci 10:127. CrossRef Medline

Ilieva H, Polymenidou M, Cleveland DW (2009) Non-cell-autonomous toxicity in neurodegenerative disorders: ALS and beyond. J Cell Biol 187: 761-772. CrossRef Medline

Ionescu A, Zahavi EE, Gradus T, Ben-Yaakov K, Perlson E (2016) Compartmental microfluidic system for studying muscle-neuron communication and neuromuscular junction maintenance. Eur J Cell Biol 95:69-88. CrossRef Medline

Jaarsma D, Teuling E, Haasdijk ED, De Zeeuw CI, Hoogenraad CC (2008) Neuron-specific expression of mutant superoxide dismutase is sufficient to induce amyotrophic lateral sclerosis in transgenic mice. J Neurosci 28:2075-2088. CrossRef Medline

Jiang SX, Whitehead S, Aylsworth A, Slinn J, Zurakowski B, Chan K, Li J, Hou ST (2010) Neuropilin 1 directly interacts with fer kinase to mediate semaphorin 3A-induced death of cortical neurons. J Biol Chem 285: 9908-9918. CrossRef Medline

Kaneko S, Iwanami A, Nakamura M, Kishino A, Kikuchi K, Shibata S, Okano HJ, Ikegami T, Moriya A, Konishi O, Nakayama C, Kumagai K, Kimura T, Sato Y, Goshima Y, Taniguchi M, Ito M, He Z, Toyama Y, Okano H (2006) A selective Sema3A inhibitor enhances regenerative responses and functional recovery of the injured spinal cord. Nat Med 12:13801389. CrossRef Medline

Kaplan A, Spiller KJ, Towne C, Kanning KC, Choe GT, Geber A, Akay T, Aebischer P, Henderson CE (2014) Neuronal matrix metalloproteinase9 is a determinant of selective neurodegeneration. Neuron 81:333-348. CrossRef Medline

Kolodkin AL, Levengood DV, Rowe EG, Tai YT, Giger RJ, Ginty DD (1997) Neuropilin is a semaphorin III receptor. Cell 90:753-762. CrossRef Medline
Körner S, Böselt S, Wichmann K, Thau-Habermann N, Zapf A, Knippenberg S, Dengler R, Petri S (2016) The axon guidance protein semaphorin 3A is increased in the motor cortex of patients with amyotrophic lateral sclerosis. J Neuropathol Exp 75:326-333. CrossRef Medline

Lee J, Hyeon SJ, Im H, Ryu H, Kim Y, Ryu H (2016) Astrocytes and microglia as non-cell-autonomous players in the pathogenesis of ALS. Exp Neurobiol 25:233-240. CrossRef Medline

Lemmens R, Moore MJ, Al-Chalabi A, Brown RH Jr, Robberecht W (2010) RNA metabolism and the pathogenesis of motor neuron diseases. Trends Neurosci 33:249-258. CrossRef Medline

Lino MM, Schneider C, Caroni P (2002) Accumulation of SOD1 mutants in postnatal motoneurons does not cause motoneuron pathology or motoneuron disease. J Neurosci 22:4825-4832. CrossRef Medline

Loeffler JP, Picchiarelli G, Dupuis L, Gonzalez De Aguilar JL (2016) The role of skeletal muscle in amyotrophic lateral sclerosis. Brain Pathol 26:227236. CrossRef Medline

Luo Y, Raible D, Raper JA (1993) Collapsin: a protein in brain that induces the collapse and paralysis of neuronal growth cones. Cell 75:217-227. CrossRef Medline

Manzano R, Toivonen JM, Calvo AC, Oliván S, Zaragoza P, Muñoz MJ, Montarras D, Osta R (2012) Quantity and activation of myofiberassociated satellite cells in a mouse model of amyotrophic lateral sclerosis. Stem Cell Rev Reports 8:279-287. CrossRef Medline

Mead RJ, Bennett EJ, Kennerley AJ, Sharp P, Sunyach C, Kasher P, Berwick J, Pettmann B, Battaglia G, Azzouz M, Grierson A, Shaw PJ (2011) Optimised and rapid pre-clinical screening in the SOD1G93A transgenic mouse model of amyotrophic lateral sclerosis (ALS). PLoS One 6:e23244. CrossRef Medline

Miller TM, Kim SH, Yamanaka K, Hester M, Umapathi P, Arnson H, Rizo L, Mendell JR, Gage FH, Cleveland DW, Kaspar BK (2006) Gene transfer demonstrates that muscle is not a primary target for non-cellautonomous toxicity in familial amyotrophic lateral sclerosis. Proc Natl Acad Sci U S A 103:19546-19551. CrossRef Medline

Molasy M, Walczak A, Szaflik J, Szaflik JP, Majsterek I (2017) MicroRNAs in glaucoma and neurodegenerative diseases. J Hum Genet 62:105-112. CrossRef Medline

Molofsky AV, Kelley KW, Tsai HH, Redmond SA, Chang SM, Madireddy L, Chan JR, Baranzini SE, Ullian EM, Rowitch DH (2014) Astrocyteencoded positional cues maintain sensorimotor circuit integrity. Nature 509:189-194. CrossRef Medline

Moloney EB, de Winter F, Verhaagen J (2014) ALS as a distal axonopathy: molecular mechanisms affecting neuromuscular junction stability in the presymptomatic stages of the disease. Front Neurosci 8:252. CrossRef Medline

Moloney EB, Hobo B, De Winter F, Verhaagen J (2017) Expression of a mutant SEMA3A protein with diminished signalling capacity does not alter ALS-related motor decline, or confer changes in NMJ plasticity after BotoxA-induced paralysis of male gastrocnemic muscle. PLoS One 12: e0170314. CrossRef Medline

Mulder DW, Kurland LT, Offord KP, Beard CM (1986) Familial adult motor neuron disease: amyotrophic lateral sclerosis. Neurology 36:511-517. CrossRef Medline

Musarò A (2013) Understanding ALS: new therapeutic approaches. FEBS J 280:4315-4322. CrossRef Medline

Nachmany H, Wald S, Abekasis M, Bulvik S, Weil M (2012) Two potential biomarkers identified in mesenchymal stem cells and leukocytes of patients with sporadic amyotrophic lateral sclerosis. Dis Markers 32:211220. CrossRef Medline

Nagai M, Re DB, Nagata T, Chalazonitis A, Jessell TM, Wichterle H, Przedborski S (2007) Astrocytes expressing ALS-linked mutated SOD1 release factors selectively toxic to motor neurons. Nat Neurosci 10:615-622. CrossRef Medline

Nakamura F, Kalb RG, Strittmatter SM (2000) Molecular basis of semaphorin-mediated axon guidance. J Neurobiol 44:219-229. CrossRef Medline

Perlson E, Jeong GB, Ross JL, Dixit R, Wallace KE, Kalb RG, Holzbaur EL (2009) A switch in retrograde signaling from survival to stress in rapidonset neurodegeneration. J Neurosci 29:9903-9917. CrossRef Medline

Peters OM, Ghasemi M, Brown RH Jr (2015) Emerging mechanisms of molecular pathology in ALS. J Clin Invest 125:1767-1779. CrossRef Medline

Philips T, Rothstein JD (2015) Rodent models of amyotrophic lateral sclerosis. Curr Protoc Pharmacol 69:5.67.1-21. CrossRef Medline 
Rakhit R, Crow JP, Lepock JR, Kondejewski LH, Cashman NR, Chakrabartty A (2004) Monomeric $\mathrm{Cu}, \mathrm{Zn}$-superoxide dismutase is a common misfolding intermediate in the oxidation models of sporadic and familial amyotrophic lateral sclerosis. J Biol Chem 279:15499-15504. CrossRef Medline

Rickham PP (1964) Human experiment. Code of ethics of the world medical association. Declaration of helsinki. Br Med J 2:177. Medline

Rosen DR, Siddique T, Patterson D, Figlewicz DA, Sapp P, Hentati A, Donaldson D, Goto J, O'Regan JP, Deng HX (1993) Mutations in Cu/Zn superoxide dismutase gene are associated with familial amyotrophic lateral sclerosis. Nature 362:59-62. CrossRef Medline

Rotem N, Magen I, Ionescu A, Gershoni-Emek N, Altman T, Costa CJ, Gradus T, Pasmanik-Chor M, Willis DE, Ben-Dov IZ, Hornstein E, Perlson E (2017) ALS along the axons: expression of coding and noncoding RNA differs in axons of ALS models. Sci Rep 7:44500. CrossRef Medline

Scrutton NS, Deonarain MP, Berry A, Perham R (1992) Cooperativity induced by a single mutation at the subunit interface of a dimeric enzyme: glutathione reductase. Science 258:1140-1143. CrossRef Medline

Shi P, Wei Y, Zhang J, Gal J, Zhu H (2010) Mitochondrial dysfunction is a converging point of multiple pathological pathways in amyotrophic lateral sclerosis. J Alzheimer's Dis 20:S311-S324. CrossRef Medline

Shirvan A, Kimron M, Holdengreber V, Ziv I, Ben-Shaul Y, Melamed S, Melamed E, Barzilai A, Solomon AS (2002) Anti-semaphorin 3A antibodies rescue retinal ganglion cells from cell death following optic nerve axotomy. J Biol Chem 277:49799-49807. CrossRef Medline

Tsitkanou S, Della Gatta PA, Russell AP (2016) Skeletal muscle satellite cells, mitochondria, and microRNAs: their involvement in the pathogenesis of ALS. Front Physiol 7:403. CrossRef Medline

Van Battum EY, Brignani S, Pasterkamp RJ (2015) Axon guidance proteins in neurological disorders. Lancet Neurol 14:532-546. CrossRef Medline

Venkova K, Christov A, Kamaluddin Z, Kobalka P, Siddiqui S, Hensley K
(2014) Semaphorin 3A signaling through neuropilin-1 is an early trigger for distal axonopathy in the SOD1G93A mouse model of amyotrophic lateral sclerosis. J Neuropathol Exp Neurol 73:702-713. CrossRef Medline

Villain G, Poissonnier L, Noueihed B, Bonfils G, Rivera JC, Chemtob S, Soncin F, Mattot V (2018) miR-126-5p promotes retinal endothelial cell survival through SetD5 regulation in neurons. Development 145: dev156232. CrossRef Medline

Vilmont V, Cadot B, Vezin E, Le Grand F, Gomes ER (2016) Dynein disruption perturbs post-synaptic components and contributes to impaired MuSK clustering at the NMJ: implication in ALS. Sci Rep 6:27804. CrossRef Medline

Wen X, Tan W, Westergard T, Krishnamurthy K, Markandaiah SS, Shi Y, Lin S, Shneider NA, Monaghan J, Pandey UB, Pasinelli P, Ichida JK, Trotti D (2014) Antisense proline-arginine RAN dipeptides linked to C9ORF72ALS/FTD form toxic nuclear aggregates that initiate in vitro and in vivo neuronal death. Neuron 84:1213-1225. CrossRef Medline

Wen X, Westergard T, Pasinelli P, Trotti D (2017) Pathogenic determinants and mechanisms of ALS/FTD linked to hexanucleotide repeat expansions in the C9orf72 gene. Neurosci Lett 636:16-26. CrossRef Medline

Wong M, Martin LJ (2010) Skeletal muscle-restricted expression of human SOD1 causes motor neuron degeneration in transgenic mice. Hum Mol Genet 19:2284-2302. CrossRef Medline

Worzfeld T, Offermanns S (2014) Semaphorins and plexins as therapeutic targets. Nat Rev Drug Discov 13:603-621. CrossRef Medline

Zahavi EE, Ionescu A, Gluska S, Gradus T, Ben-Yaakov K, Perlson E (2015) A compartmentalized microfluidic neuromuscular co-culture system reveals spatial aspects of GDNF functions. J Cell Sci 128:1241-1252. CrossRef Medline

Zahavi EE, Maimon R, Perlson E (2017) Spatial-specific functions in retrograde neuronal signalling. Traffic 18:415-424. CrossRef Medline 